Preprints of the

Max Planck Institute for

Research on Collective Goods

Bonn 2008/30

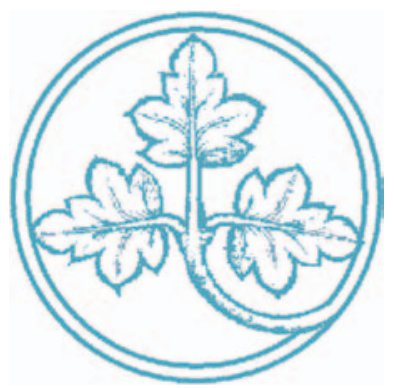

Vertical Integration, Raising Rivals' Costs and Upstream Collusion

Hans-Theo Normann

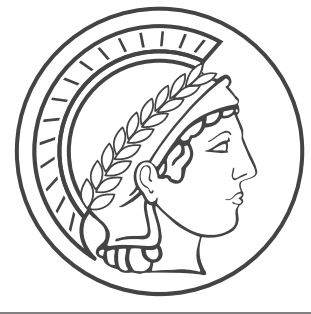




\title{
Vertical Integration, Raising Rivals' Costs and Upstream Collusion
}

\author{
Hans-Theo Normann
}

August 2008 


\title{
Vertical Integration, Raising Rivals' Costs and Upstream Collusion*
}

\author{
Hans-Theo Normann ${ }^{\dagger}$ \\ Max-Planck Institute \\ Bonn
}

July 30,2008

\begin{abstract}
This paper analyzes the impact vertical integration has on upstream collusion when the price of the input is linear. As a first step, the paper derives the collusive equilibrium that requires the lowest discount factor in the infinitely repeated game when one firm is vertically integrated. It turns out this is the joint-profit maximum of the colluding firms. The discount factor needed to sustain this equilibrium is then shown to be unambiguously lower than the one needed for collusion in the separated industry. While the previous literature has found it difficult to reconcile raising-rivals-costs strategies following a vertical merger with equilibrium behavior in the static game, they are subgame perfect in the repeated game studied here.
\end{abstract}

Keywords: collusion, foreclosure, raising rivals' costs, vertical integration

JEL classification numbers: D43, L13, L23, L40

${ }^{*}$ I am much indebted to an anonymous referee whose valuable suggestions significantly improved the paper. I am also grateful to Christoph Engel, Dirk Engelmann, Jos Jansen, Volker Nocke, conference participants at the EARIE meetings in Porto and the IIOC in Arlington, and seminar audiences in Berlin (TU), East Anglia, Göttingen, Mannheim and Zurich for helpful comments. A previous version of the paper was entitled "Equilibrium Vertical Foreclosure in the Repeated Game".

${ }^{\dagger}$ Max Planck Institute for Research on Collective Goods, fax: +49 228 91416-55, email: normann@coll.mpg.de. 


\section{Introduction}

The anticompetitive effects of vertical integration continue to be an active and controversial topic of research in industrial economics. Antitrust decisions hostile towards vertical mergers in the US in the 1950s and 1960s were based on the idea that vertical integration can harm competition by removing resources from the input market, thereby leveraging monopoly power from one market to another. These arguments have been labeled as naïve (Rey and Tirole, 2007) because they lacked a rigorous formal basis. The more recent post-Chicago theories of vertical mergers (for example, Salinger, 1988; Hart and Tirole, 1990; O'Brien and Schaffer, 1992) formally derived many of the conclusions of the older theories. In game-theoretic models a connection is established between vertical integration and potentially anticompetitive outcomes. The post-Chicago theories of vertical integration differ in various details, for example, assumptions about the integrated firm's market power and the contractual arrangements between the parties involved. There are several dominating approaches though, including the "raising-rivals'-costs" and the "facilitating-collusion" theory (Riordan, 2008). ${ }^{1}$

The raising-rivals'-costs theory of vertical merger highlights the possibility that vertically integrated firms may drive up the price of the input its unintegrated downstream rivals pay. In a seminal contribution, Ordover, Saloner and Salop (1990), henceforth OSS (1990), argue that vertical mergers might change the incentive to compete in the input market. When a vertically integrated firm withdraws from the input market, upstream price competition becomes weaker. This reduction in upstream competition implies a higher price for the input which means higher cost for the non-integrated downstream firms. Since the downstream unit of the integrated firm benefits when its rivals' costs are raised, the integrated firm is better off withdrawing from the market compared to the case where it competes in the input market. In other words, it pays for the integrated firm to forgo business with non-integrated downstream firms and instead gain from its downstream rivals becoming less competitive as a result of the increased the price of the input.

The facilitating-collusion theory argues that vertical integration might make price agreements among upstream firms easier. This concern has been expressed in the 1984 Non-horizontal Merger

\footnotetext{
${ }^{1}$ Riordan (2008) lists the "restoring monopoly power" as a third major post-Chicago theory of anticompetitive vertical merger. On this approach, see Hart and Tirole (1990), Martin, Normann and Snyder (2001), and Rey and Tirole (2007). Riordan's classification includes two further groups of theories, "eliminating markups" and "single monopoly profit", which he attributes to the Chicago School.
} 
Guidelines and in several cartel cases (see Riordan, 2008). The idea has recently been formalized in a dynamic model by Nocke and White (2007). ${ }^{2}$ They analyze collusion in the infinitely repeated game among upstream firms which charge two-part tariffs for the input. Nocke and White compare the minimum discount factor required for collusion where one or more firms are vertically integrated to the case of vertical separation. It turns out that vertical integration unambiguously facilitates collusion.

This paper builds on and adds to both the raising-rivals'-costs and the facilitating-collusion theory of vertical integration. ${ }^{3}$ It combines OSS' (1990) idea that raising-rivals'-costs effects change the incentives of vertically integrated firms to compete in the input market with the presumption that vertical integration facilitates collusion. In terms of the modeling strategy, the paper can merge these two strands of the literature because they share several central assumptions (e.g., bilateral oligopoly with perfect competition upstream and imperfect competition downstream). In this paper, the stage game is modeled as in OSS (1990) and allows for a raising-rivals'-costs effect but, in contrast to the static model of OSS (1990), this paper studies repeated interaction in a dynamic model. The analysis of the impact of vertical integration on collusion is similar to Nocke and White (2007). However, departing from Nocke and White (2007) and following OSS (1990), downstream firms pay a linear price for the input here.

In a first step, the paper provides a general analysis of upstream collusion in the presence of an integrated firm. The analysis focuses on the collusive equilibrium that requires the lowest discount factor (see Compte et al., 2002, for a similar analysis). It turns out that this equilibrium is the one where the profits of the colluding firms are maximized. In other words, the payoff dominant equilibrium also relaxes the incentive constraint as far as possible. Other equilibria exist but they require a higher discount factor and give lower profits to the colluding players. A general finding of the analysis of collusion involving an integrated firm is that, because the integrated firm operates both upstream and downstream, collusive pricing is rather different from the standard case of upstream collusion among vertically separated firms. One of these differences is that the downstream unit of the integrated firm is involved in the collusion in that the price of the downstream integrated firm is higher than its myopic best reply. This result confirms and

\footnotetext{
${ }^{2}$ Riordan and Salop (1995) and Chen (2001) are also associated with the facilitating-collusion theory.

${ }^{3}$ The first version of the present paper, Normann (2004), was developed independently of Nocke and White's first version, Nocke and White (2003).
} 
extends Chen's (2001) findings.

Based on this preparatory analysis, the paper derives two main results. First, the paper's contribution to the raising-rivals'-costs literature is to show that an outcome similar to the one analyzed in OSS (1990) can actually be sustained as a subgame perfect Nash equilibrium. Second, the contribution to the facilitating collusion theory is that vertical integration facilitates collusion also with linear contracts. To appraise these findings, more background information and details of the results are needed.

Regarding the significance of the first main result, one needs to recall that OSS' raising-rivals'costs argument has been criticized as not robust. Hart and Tirole (1990) and Reiffen (1992) pointed out that, even though withdrawing from the input market is a profitable strategy for the integrated firm ex ante, it has an incentive to compete in the input market ex post. Therefore, vertical integration does not make any difference at all in the static Nash equilibrium. The intuition of this argument is that, since the price of the input increases once the integrated firm withdraws from the input-good market, the integrated firm has an incentive to deviate. Rather than withdraw from the input market, it will re-enter and undercut the upstream competitors' price in order to gain the business of the non-integrated downstream firms. The integrated firm's upstream rivals will anticipate such a deviation and will expect the re-entry in the market. In that case, upstream competition is the same as without vertical integration in the static game.

Several papers in the literature have shown before that the outcome OSS (1990) propose can be made robust and compatible with Nash equilibrium behavior (see OSS, 1992; Choi and Yi, 2000; Church and Gandal, 2000). ${ }^{4}$ However, these papers are only partially successful in confirming the OSS (1990) approach as they circumvent, to some extent, the problem posed in the original analysis. For example, in OSS (1992), non-integrated downstream firms procure the input in a descending-price auction. In such a scenario, the integrated firm will drop out early in the auction, the input market will be monopolized by the non-integrated upstream firm and, hence, the outcome is indeed as in OSS (1990). Note that deviation from this equilibrium is prevented by the rules of the auction. By dropping out, the integrated firm commits itself not to re-enter. Thus, if available, commitment works in this case, but this does not answer the question raised by Hart and Tirole (1990) and Reiffen (1992). Their point is whether commitment will be available

\footnotetext{
${ }^{4}$ For less closely related raising-rivals-costs models, see also Riordan (1998) and Chen and Riordan (2007).
} 
at all, and why vertical merger should enable to commit. Arguably, few markets are organized as descending-price auctions. Therefore, it is still subject to debate whether the rasing-rivals'costs theory has implications beyond the perhaps somewhat restrictive scenarios the literature has hitherto suggested. ${ }^{5}$

The present paper does not impose any assumptions on the extensive form that seem overly narrow. The assumption of repeated interaction is simple and should be plausible for many industries. What the paper shows is that, even though the raising-rivals'-costs strategy is not tenable as an equilibrium of the static game, it can be supported in the repeated game if repetition is frequent enough. This result confirms the informal arguments of Riordan and Salop (1995) that OSS' (1990) rasing-rivals'-costs idea can be saved from the Hart and Tirole (1990) and Reiffen (1992) criticism with repeated interaction.

Of course, the result that the raising-rivals'-costs strategy can be an equilibrium in the repeated game is not particularly surprising. We know from the Folk Theorem that almost anything can be part of a repeated-game equilibrium. Thus, this finding alone is not sufficient to support a policy conclusion against vertical mergers. At this point, the second main result of the paper-that vertical integration facilitates collusion - comes into play. Given that upstream collusion requires a lower discount factor when one firm vertically integrates, the raising-rivals'-costs strategy of the integrated firm can actually be anti-competitive. For a certain range of discount factors, the input market will be collusive only when there is vertical integration. This implies that firms have a motive for anti-competitive vertical merger, as suggested by OSS (1990).

The facilitating-collusion theory has so far been restricted to two-part tariffs (Nocke and White, 2007). It is well known that two-part tariffs are more efficient than linear contracts in simple settings (Tirole, 1988). However, in more complex environments, Iyer and Villas-Boas (2003) and Milliou, Petrakis and Vettas (2005) identify plausible cases where linear contracts emerge as the endogenous form of contracting. Empirically, both forms of contracts seem relevant (see, e.g., Inderst and Valetti, 2007, who analyze linear contracts because of their relevance in supermarket procurement). Thus, extending the results for the case of linear tariffs significantly strengthens

\footnotetext{
${ }^{5}$ Choi and Yi (2000) assume that the integrated upstream firm can produce a specialized input for its downstream division. The specialized input serves as a technological commitment not to supply the external input market. Similarly, in Church and Gandal (2000), the final good consists of a hardware component and complementary software. When a hardware and a software firm integrate, they commit themselves not to compete by making the software incompatible with rival technologies.
} 
the facilitating-collusion argument and should add to its policy relevance.

The paper further considers alternative scenarios which could potentially challenge the significance of the two main results. First, as noted already by OSS (1990), the non-integrated downstream firms have an incentive for counter merger when their costs are raised. A successful counter merger would eliminate the raising-rivals'-costs effect and therefore the initial vertical merger would not be worthwhile. OSS (1990) show that the counter merger can be prevented when the integrated firm lowers the price of the input to such an extent that a counter merger does not pay. The same argument also holds in the repeated-game setting of this paper although there is a drawback. Upstream collusion becomes less profitable and the critical discount factor increases when the price is lowered. Second, there is the possibility of downstream collusion. In an example with linear demand, the paper shows that there exists an incentive for vertical merger and upstream collusion even when downstream collusion is a possibility.

The remainder of the paper is organized as follows. Sections 2 to 4 set up the modeling framework and restate some of the results in the literature for this framework. Section 2 introduces the market model and analyzes the static game for both the separated and vertically integrated industries. OSS' (1990) main argument is reviewed, and the Section concludes with Hart and Tirole (1990) and Reiffen's (1992) point that vertical integration does not affect competition in the static game. Section 3 introduces the repeated-game model. Section 4 provides the analysis of the benchmark of collusion in the vertically separated industry. Sections 5 and 6 contain the main contributions of the paper. Section 5 is on upstream collusion with vertical integration. Despite the aforementioned differences to the standard model of collusion (without integration), it is possible to compare the minimum discount factors required for collusion. This is done in Section 6 where it is shown that vertical integration facilitates collusion. Section 6 also discusses the effects underlying this result and compares the results to those of Nocke and White (2007). It further provides extensions of the model to bilateral oligopoly and an example with linear demand. In Section 6, there is also a welfare analysis of vertical integration and a treatment of the case where the downstream unit of the integrated firm operates as a profit center. Section 7 analyzes two alternative scenarios (counter merger and downstream collusion). Section 8 is the conclusion. 


\section{Model and static Nash equilibrium}

Apart from minor differences, the stage-game is as in OSS (1990). There are $n=2$ upstream firms and $m=2$ downstream firms. (The main results of the paper are generalized below for the $n, m>2$ case). Call the two upstream firms $U 1$ and $U 2$, and the two downstream firms $D 1$ and $D 2$. The integrated firm will be called $U 1-D 1$. The upstream firms produce a homogenous input. $D 1$ and $D 2$ transform the input on a one-to-one basis into a symmetrically differentiated final good.

The downstream level is modeled as follows. Downstream firms pay a linear price for the input which constitutes their only cost. Define $c_{i}$ as the price per unit firm $D i$ pays. There is differentiated price competition at the downstream level and $Q_{i}\left(p_{i}, p_{j}\right)$ denotes the demand function of $D i, i, j=1,2, i \neq j$. Symmetry implies that sales depend on prices but not on the identities of the firms, that is, $Q_{1}\left(p_{1}, p_{2}\right)=Q_{2}\left(p_{2}, p_{1}\right)$. $D i$ 's profits are

$$
\pi_{D i}=\left(p_{i}-c_{i}\right) Q_{i}\left(p_{i}, p_{j}\right), \quad i, j=1,2, i \neq j .
$$

We impose the following assumptions on demand. Demand functions $Q_{i}\left(p_{i}, p_{j}\right)$ are twice continuously differentiable with $\partial Q_{i} / \partial p_{i}<0, \partial Q_{i} / \partial p_{j}>0$, and $\partial Q_{i} / \partial p_{i}+\partial Q_{i} / \partial p_{j}<0, i, j=1,2$, $i \neq j$. These assumptions ensure downward sloping demand with substitute goods where the effect of a change in a firm's own prices dominates the effect resulting from a change of the rival firm's price. Further, we assume that goods are strategic complements, that is, $\partial^{2} \pi_{D i} / \partial p_{i} \partial p_{j}>0$. A final assumption is that $\partial^{2} \pi_{D i} / \partial p_{i}^{2}+\partial^{2} \pi_{D i} / \partial p_{i} \partial p_{j}<0$. This assumption implies that own effects dominate cross effects also in terms of the slope of the demand function. Together with the other assumptions, this is sufficient to ensure the existence of a unique Nash equilibrium of the stage game. ${ }^{6}$

Let $p_{i}^{*}\left(c_{i}, c_{j}\right), i, j=1,2, i \neq j$, denote the static Nash equilibrium prices at the downstream level. In the static Nash equilibrium, the input prices $\left(c_{i}, c_{j}\right)$ sufficiently describe downstream competition, and we will use $Q_{i}^{*}\left(c_{i}, c_{j}\right)$ as a reduced form for $Q_{i}\left(p_{i}^{*}\left(c_{i}, c_{j}\right), p_{j}^{*}\left(c_{j}, c_{i}\right)\right)$, and $\pi_{D i}^{*}\left(c_{i}, c_{j}\right)$ for $\pi_{D i}=\left(p_{i}^{*}\left(c_{i}, c_{j}\right)-c_{i}\right) Q_{i}^{*}\left(c_{i}, c_{j}\right)$.

Given the above assumptions, OSS (1990) show that raising the cost of a downstream rival is

\footnotetext{
${ }^{6}$ The assumptions made to ensure a unique static Nash equilibrium merely simplify the analysis. Under weaker assumptions, the stage game has multiple equilibria and one would need to distinguish between stable and unstable equilibria (see OSS, 1990). Note also that somewhat weaker conditions might be sufficient to guarantee existence and uniqueness (see Vives, 1999).
} 
profitable. That is,

$$
\frac{\partial \pi_{D i}^{*}\left(c_{i}, c_{j}\right)}{\partial c_{j}}=\left(p_{i}-c_{i}\right) \frac{\partial Q_{i}\left(p_{i}, p_{j}\right)}{\partial p_{j}} \frac{\partial p_{j}^{*}\left(c_{i}, c_{j}\right)}{\partial c_{j}}>0, i, j=1,2, i \neq j,
$$

as follows from the envelope theorem.

We now turn to the upstream level. $U 1$ and $U 2$ have constant marginal cost which we set equal to zero. ${ }^{7}$ The upstream firms are assumed to be perfect Bertrand competitors. This implies that the lower of the two prices the upstream firms set constitutes the price of the input. Given the price of the input, downstream firms purchase the number of units they require, $Q_{i}\left(p_{i}, p_{j}\right)$ (if they procure externally at all). We will specify below how much the downstream firms purchase from the two upstream firms when both upstream firms charge the same price.

When no firm is vertically integrated, upstream competition à la Bertrand implies Nash equilibrium prices equal to (zero) marginal cost on the input market. This static Nash equilibrium is unique. Both downstream firms purchase the good externally on the input market and they pay the same price for it. So, we have $c_{1}=c_{2}=0$.

When $U 1$ and $D 1$ are integrated, the downstream segment of $U 1-D 1$ obtains the input internally at $c_{1}=0$. The reason is that, for an integrated firm, the effective price of the input is always equal to own marginal production cost (Bonanno and Vickers, 1988). In this case, we have $c_{1}=0$ accordingly. Since $D 2$ only purchases the input externally, let $c_{2}$ denote the price of the input when $U 1$ and $D 1$ are integrated. ${ }^{8}$

The novel insight of OSS (1990) was to show that vertical integration may change the incentives to compete in the input market. If $U 1-D 1$ can credibly commit to withdraw from the input market, $U 2$ will became the sole supplier of $D 2$. In that case, $U 2$ will charge some $c_{2}>0$ for the input and $U 1-D 1$ earns $\pi_{D 1}^{*}\left(0, c_{2}\right)$. Suppose instead that $U 1-D 1$ competes in the input market. In that case, Bertrand competition implies $c_{2}=0$ and $U 1-D 1$ earns $\pi_{D 1}^{*}(0,0)$. Comparing the two outcomes, we find that $U 1-D 1$ makes no upstream profit in either case, but, when withdrawing from the input market, it makes a higher downstream profit, $\pi_{D 1}^{*}\left(0, c_{2}\right)>\pi_{D 1}^{*}(0,0)$, due to the raising-rivals'-costs effect (2). Hence, $U 1-D 1$ prefers to commit to withdraw from the input market.

\footnotetext{
${ }^{7}$ The assumption of zero marginal cost is made to simplify the analysis but it is not necessarily innocuous as it precludes certain types of punishment where firms price below cost (e.g., Abreu, 1988). See also footnote 9.

${ }^{8}$ The notation is deliberately sloppy here. Strictly speaking, $c_{2}$ denotes $D 2$ 's input cost and not the price of an upstream firm. We refrain from introducing extra notation for upstream firms' actions as the (lowest) posted price on the input market is always equal to $D 2$ 's cost.
} 
However, absent commitment, $U 1-D 1$ has an incentive to deviate in this situation (as emphasized by Hart and Tirole, 1990, and Reiffen, 1992). It will re-enter the input market, contrary to its claim to withdraw, and undercut $U 2$ 's input price. As $U 2$ will anticipate this deviation, the static Nash equilibrium has both $U 1-D 1$ and $U 2$ charging a price equal to marginal cost, that is, $c_{1}=c_{2}=0$ just as in the case without integration. $U 2$ earns zero profits and $U 1-D 1$ earns $\pi_{D 1}^{*}(0,0)$ in the static Nash equilibrium. The following Proposition summarizes these findings.

Proposition 1 In the static game, the U1-D1 merger does not have any impact as the input market is competitive both with and without the integration.

\section{Repeated-game framework}

Consider now the infinitely repeated game. Time is indexed from $t=0, \ldots, \infty$. Firms discount future profits with a common factor $\delta$, where $\delta \in(0,1)$. When analyzing the repeated game, denote by $\pi_{i}^{c}$ the profit a firm earns when both firms adhere to collusion. We require $\pi_{i}^{c}$ to be strictly larger than the profit $i$ makes in the static Nash equilibrium such that collusive equilibria are individually rational. Let $\pi_{i}^{d}$ denote the profit when firm $i$ defects. $\pi_{i}^{p}$ is the profit when punishment is triggered. We employ simple trigger strategies with reversion to the static Nash equilibrium here. ${ }^{9}$

We look for collusive equilibria that are subgame perfect. In order to prevent defection in period $t=0$, the one-time gain from deviating today, $\pi_{i}^{d}-\pi_{i}^{c}$, must be weakly smaller than the loss due to punishment, $\pi_{i}^{c}-\pi_{i}^{p}$, made in every future period $t=1, \ldots, \infty$ for both firms. That is,

$$
\pi_{i}^{d}-\pi_{i}^{c} \leq\left(\pi_{i}^{c}-\pi_{i}^{p}\right) \frac{\delta}{1-\delta} ; i=1,2 .
$$

Condition (3) can also be expressed in the following way

$$
\delta \geq \frac{\pi_{i}^{d}-\pi_{i}^{c}}{\pi_{i}^{d}-\pi_{i}^{p}}:=\delta_{i} ; i=1,2,
$$

where $\delta_{i}$ denotes the minimum discount factor required for firm $i$ to adhere to collusion. In words, whenever the actual discount factor, $\delta$, is as least as high as the larger of the two minimum discount

\footnotetext{
${ }^{9}$ As demonstrated in Nocke and White (2007), using simple penal codes as an optimal punishment scheme (Abreu, 1988) actually fails in extensive-form games like this. The downstream firms will be involved in the most severe punishment scheme and the punishment may depend on the identity and deviation price of the deviator.
} 
factors, collusion is feasible. We will sometimes also use $\underline{\delta}=\max \left\{\delta_{1}, \delta_{2}\right\}$ such that $\delta \geq \underline{\delta}$ is required for collusion.

When analyzing collusion, we will derive the collusive Nash equilibrium that requires the lowest discount factor. As is common in this literature (Bernheim and Whinston, 1990; Compte et al., 2002; Nocke and White, 2007), we assume that firms are able to set market shares in such a way that $\underline{\delta}$ is minimized.

\section{Upstream collusion in the vertically separated industry}

In the absence of vertical integration, it is straightforward to solve for the minimum discount factor. There are two independent upstream firms, $U 1$ and $U 2$, and two downstream firms, $D 1$ and $D 2$. Both downstream firms purchase the input externally on the market. Suppose upstream firms collude on some price for the input. Denoting this collusive input price by $c$, we obtain $c_{1}=c_{2}=c$.

Let $\pi^{c o l}$ denote total upstream industry profit when collusion is successful, that is, $\pi^{c o l}=$ $c\left(Q_{1}^{*}(c, c)+Q_{2}^{*}(c, c)\right)$. Let $s \in[0,1]$ denote the market share $U 1$ has in the input market. $U 1$ and $U 2$ earn $\pi_{1}^{c}=s \pi^{c o l}$ and $\pi_{2}^{c}=(1-s) \pi^{c o l}$ when colluding, respectively. When firm $i$ defects, it will earn $\pi_{i}^{d}=\pi^{c o l}$ by undercutting the collusive price $c$ by a small amount. Nash reversions yield $\pi_{i}^{p}=0$ for both firms.

Let $\delta_{U i}$ denote the minimum discount factor required for $U i$ to adhere to collusion. Using (4), the minimum discount factors required are

$$
\delta_{U 1}=\frac{\pi^{c o l}-s \pi^{c o l}}{\pi^{c o l}}=1-s
$$

and

$$
\delta_{U 2}=\frac{\pi^{c o l}-(1-s) \pi^{c o l}}{\pi^{c o l}}=s .
$$

We have $\delta_{U 1}+\delta_{U 2}=1$, and a symmetric division of the input market, $s^{*}=1 / 2$, minimizes the discount factor required for collusion. We obtain the standard result that minimum discount factors are

$$
\delta_{U 1}=\delta_{U 2}=1 / 2
$$

when the industry is vertically separated. 
Proposition 2 In the vertically separated industry, upstream collusion can be supported as a subgame perfect Nash equilibrium if and only if $\delta \geq 1 / 2$.

As is well known, the minimum discount factor here does not depend on the level of collusive profits, $\pi^{c o l}$. Thus, firms may well choose $c$ such as to maximize $\pi^{c o l}$ as this requires the same discount factor as any other collusive profit.

\section{Upstream collusion with $U 1-D 1$ integration}

\subsection{Preliminaries}

We will now analyze the repeated game when $U 1$ and $D 1$ are vertically integrated but $U 2$ and $D 2$ are not. We will consider collusion at the upstream level, that is, an implicit agreement between $U 1-D 1$ and $U 2$. As above, let $c_{2}$ denote the price of the input.

The nature of upstream collusion changes significantly when one upstream firm is integrated. In particular, $U 1-D 1$ 's downstream price, $p_{1}$, will be part of the collusion. This is by no means to say that $U 1-D 1$ colludes with $D 2$ at the downstream level. However, $p_{1}$ affects both the collusive and the defection profits of $U 1-D 1$ and $U 2$ at the upstream level (more on this below). Therefore, $U 1-D 1$ will take these effects into account when setting $p_{1}$, that is, the downstream price $p_{1}$ will be chosen to optimize the feasibility of upstream collusion. ${ }^{10}$ Note that, while a deviation from the collusive downstream price only would trigger the punishment, this would not be rational as the integrated firm would obtain strictly higher defection payoffs when it also deviates at the upstream level.

As above in the analysis of the separated industry, market shares will be set such as to minimize the incentives to deviate. Let $s$ denote $U 1-D 1$ 's market share in the input market and $1-s$ is $U 2$ 's market share. Here, market shares refer to the external input market, with an output of $Q_{2} \cdot{ }^{11}$ By contrast, with vertical separation, $s$ and $1-s$ refer to $D 1$ and $D 2$ 's purchases, that is, $Q_{1}+Q_{2}$.

\footnotetext{
${ }^{10}$ In Section 6.6 , we will consider a special case where $p_{1}$ is not collusive and where $p_{1}=p_{1}^{*}$ maximizes $D 1$ 's short-run profit instead.

${ }^{11}$ In the case of vertical integration, $D 2$ only purchases the input externally on the market. However, theoretically, $D 1$ might want to purchase input from $U 2$ as this is an effective way for making side payments. This possibility, considered below, would imply $s^{*}<0$.
} 


\subsection{Benchmarks}

Before stating the results, we need some more notation and two useful benchmarks. In terms of notation, whenever $p_{1}$ is not equal to $p_{1}^{*}\left(c_{1}, c_{2}\right)$, we cannot apply the $Q_{i}^{*}\left(c_{i}, c_{j}\right)$ notation for the downstream outputs anymore. In such cases, let $Q_{1}\left(p_{1}, p_{2}\left(c_{2}\right)\right)$ and $Q_{2}\left(p_{2}\left(c_{2}\right), p_{1}\right)$ denote outputs in the sense that $p_{2}$ will be the (myopic) best reply to $p_{1}$ given $c_{2}$, and $p_{1}$ is the collusive downstream price given $c_{1}=0$ (which results from the assumption of zero marginal production cost upstream). Using this notation, collusive profits are $p_{1} Q_{1}\left(p_{1}, p_{2}\left(c_{2}\right)\right)+s c_{2} Q_{2}\left(p_{2}\left(c_{2}\right), p_{1}\right)$ and $(1-s) c_{2} Q_{2}\left(p_{2}\left(c_{2}\right), p_{1}\right)$, for $U 1-D 1$ and $U 2$, respectively.

The first benchmark is the joint-profit maximum of $U 1-D 1$ and $U 2$. The joint maximum depends on $p_{1}$ and $c_{2}$. Formally

$$
\left\{p_{1}^{j p m}, c_{2}^{j p m}\right\}:=\underset{p_{1}, c_{2}}{\arg \max } p_{1} Q_{1}\left(p_{1}, p_{2}\left(c_{2}\right)\right)+c_{2} Q_{2}\left(p_{2}\left(c_{2}\right), p_{1}\right) .
$$

Let $Q_{1}^{j p m}=Q_{1}\left(p_{1}^{j p m}, p_{2}\left(c_{2}^{j p m}\right)\right), Q_{2}^{j p m}=Q_{2}\left(p_{2}\left(c_{2}^{j p m}\right), p_{1}^{j p m}\right)$ and $\pi^{j p m}=p_{1}^{j p m} Q_{1}^{j p m}+c_{2}^{j p m} Q_{2}^{j p m}$.

The second benchmark is the price of the input that maximizes $U 2$ 's profits if it is a monopolist in the (external) input market and if $U 1-D 1$ plays its myopic best reply at the downstream level, $p_{1}^{*}\left(0, c_{2}\right)$. Denote this price by $c_{2}^{m o n}$ and define formally

$$
c_{2}^{m o n}:=\underset{c_{2}}{\arg \max } c_{2} Q_{2}^{*}\left(c_{2}, 0\right) .
$$

Accordingly, define $\pi_{2}^{m o n}:=c_{2}^{m o n} Q_{2}^{*}\left(c_{2}^{m o n}, 0\right)$. This benchmark will be important when we analyze $U 2$ 's defection profits. The input-good price $c_{2}^{\text {mon }}$ is also central to the static analysis of OSS (1990).

\subsection{Upstream collusion with $U 1-D 1$ integration: the main result}

We now state the result on collusion when $U 1$ and $D 1$ are integrated and collude with $U 2$ at the upstream level. The complete proof can be found in Appendix A.

Proposition 3 The collusive equilibrium where U1-D1 and U2 charge the joint-profit maximizing prices $c_{2}^{j p m}$ and $p_{1}^{j p m}$ requires the lowest discount factor. If $U 1-D 1$ deviates from the collusive upstream price it gets $\pi^{j p m}$ whereas $U 2$ gets $\pi_{2}^{\text {mon }}$ when it deviates. 
The Proposition indicates that collusion between $U 1-D 1$ and $U 2$ is feasible if and only if the joint-profit maximum of $U 1-D 1$ and $U 2$ (not to be confused with the industry profit maximum) can be sustained as a subgame perfect Nash equilibrium. Coordinating on a collusive equilibrium other than the joint-profit maximum of $U 1-D 1$ and $U 2$ is not worthwhile for firms as this requires a higher discount factor and reduces their joint profits. This result is stronger than the one obtained with vertical separation where the joint-profit maximum of $U 1$ and $U 2$ requires the same discount factor as any other collusive equilibrium.

One implication of Proposition 3 is that a repeated-game equilibrium exists where $D 2$ 's costs are supra-competitive. In other words, OSS (1990) raising-rival's-costs strategy can be a subgame perfect Nash equilibrium in the repeated game. This result confirms the informal arguments of Riordan and Salop (1995) that OSS' (1990) story can be saved from the Hart and Tirole (1990) and Reiffen (1992) criticism with repeated interaction. Many other collusive Nash equilibria may exist but the properties of the equilibrium in Proposition 3 (maximum profits at the lowest minimum discount factor) strengthen the case for the raising-rival's-costs story.

As mentioned in the introduction, this interpretation of the result is not particularly intriguing since we know from the Folk Theorem that many outcomes can be sustained as an equilibrium in the infinitely repeated game. Therefore, the comparison of the critical discount factor with and without vertical integration (conducted in the next section) is crucial regarding the policy implications of the analysis.

For the remainder of this section, a qualitative discussion of how upstream collusion in the presence of an integrated firm works is provided (for formal details, see Appendix A). This concerns mainly the understanding of $U 1-D 1$ 's downstream price. There are two separate issues; the collusive downstream price and the downstream price following an upstream deviation.

We start with the collusive downstream price, $p_{1}$. This price is higher than the price a nonintegrated $D 1$ would charge for two reasons. The first reason is that the integrated $U 1-D 1$ sells a positive amount of the input to $D 2$. Even in a static game, this would imply higher downstream prices (Chen, 2001). The intuition is as follows. When $U 1-D 1$ has a positive share in the external input market, it earns money not only through its own downstream outlet but also by selling input to $D 2$. Therefore, $U 1-D 1$ faces a tradeoff. Lowering $p_{1}$ implies higher profits for $D 1$ but lower sales for $D 2$ and therefore lower upstream profits. Put differently, while a separated $D 1$ would set $p_{1}$ such that its marginal profits are zero, the integrated $U 1-D 1$ 's marginal profits from selling to 
$D 2$ are positive and thus $U 1-D 1$ will charge a correspondingly higher $p_{1}$.

Chen (2001) was the first to discover this anticompetitive effect of vertical integration on downstream prices. The market model in that paper is similar to the present one although Chen analyzes a static game and allows for asymmetric upstream cost functions. Specifically, he analyzes the possibility that downstream firms choose the upstream supplier from which they will purchase the input before prices are set. In this case, vertical integration has a similar anticompetitive effect (see Chen's Lemma 1) as in this model. When the integrated firm sells some of the input to D2 (at a price higher than marginal cost), its incentives to compete at the downstream level are reduced and, thus, downstream prices are higher. Chen (2001) shows that D2 may find it worthwhile to select the integrated firm as its supplier in that case.

As mentioned, $U 1-D 1$ 's positive share in the input market would lead to increased downstream prices even in the one-shot game (all else equal). In the repeated game, there is an additional effect which drives up the downstream prices further. In the static game, the integrated firm would choose $p_{1}$ such as to maximize own profits, that is, to maximize $p_{1} Q_{1}\left(p_{1}, p_{2}\left(c_{2}^{j p m}\right)\right)+s c_{2}^{j p m} Q_{2}\left(p_{2}\left(c_{2}^{j p m}\right), p_{1}\right)$, where $s<1$. However, Proposition 3 indicates that $p_{1}$ will be chosen to maximize the joint profits of $U 1-D 1$ and $U 2$, that is, to maximize $p_{1} Q_{1}\left(p_{1}, p_{2}\left(c_{2}^{j p m}\right)\right)+c_{2}^{j p m} Q_{2}\left(p_{2}\left(c_{2}^{j p m}\right), p_{1}\right)$. In other words, in the repeated game equilibrium characterized in Proposition 3 , the integrated firm chooses $p_{1}$ as if it had a 100 percent market share upstream in a static game. Since the optimal $p_{1}$ is increasing in the market share the integrated firm has, the collusive effect of vertical integration on downstream prices is stronger in the repeated game.

Proposition 3 indicates that $p_{1}$ is also affected when an upstream firm defects. As $U 1-D 1$ operates at both industry levels, it can observe upstream deviations and can therefore respond to them by charging a downstream price different from the collusive one. No matter which firm deviates, $U 1-D 1$ will always set its downstream price such that it maximizes its short run profits after a deviation. This is because, in the case of a deviation at the upstream level in period $t$, the punishment will be triggered in $t+1$ regardless of the downstream price $U 1-D 1$ charges in $t$ and, thus, sequential rationality implies myopic profit maximization in $t$. However, $U 1-D 1$ 's downstream price following a defection will differ depending on whether $U 1-D 1$ or $U 2$ was the defector. If $U 1-D 1$ itself deviates at the upstream level, $U 1-D 1$ will capture the entire upstream profit in addition to its downstream profit and $U 2$ earns nothing. Thus, $U 1-D 1$ 's optimal downstream price maximizes the sum of upstream profits and $D 1$ 's profit. If $U 2$ is the deviator at the upstream level, $U 1-D 1$ 
does not gain any upstream profit; only $D 1$ earns money. Hence, $U 1-D 1$ 's optimal downstream price will maximize $D 1$ 's profit. Indeed, it is straightforward to see that $U 1-D 1$ will choose the short-run best response to $D 2$ 's price given $c_{2}$, that is $p_{1}^{*}\left(c_{2}\right)$, in this case. This reduces $U 2$ 's defection profits. These arguments illustrate that $U 1-D 1$ 's downstream price has a strong impact on the profitability of upstream deviations. (See also the discussion of the reaction effect below.)

The logic of downstream pricing after a defection also explains why $U 1-D 1$ and $U 2$ should coordinate on the joint-profit maximum in order to minimize the discount factor required for collusion. If there is an upstream deviation (no matter whether $U 1-D 1$ or $U 2$ is the deviator), $U 1-D 1$ will set a downstream price that does not depend on the original collusive downstream price. That is, the defection profits do not depend on the collusive downstream price either. Thus, firms should maximize collusive profits as far as possible in order to minimize the critical discount factor. A similar argument can be made regarding the collusive upstream price (see Appendix A).

\subsection{The minimum discount factor}

Collusion as described in Proposition 3 implies the following for the minimum discount factor when $U 1$ and $D 1$ are integrated. For $U 1-D 1,(3)$ becomes

$$
(1-s) c_{2}^{j p m} Q_{2}^{j p m} \leq\left(s c_{2}^{j p m} Q_{2}^{j p m}+p_{1}^{j p m} Q_{1}^{j p m}-\pi_{D 1}^{*}(0,0)\right) \frac{\delta}{1-\delta}
$$

as $\pi_{D 1}^{*}(0,0)$ is the punishment profit. For $U 2,(3)$ reads

$$
\pi_{2}^{m o n}-(1-s) c_{2}^{j p m} Q_{2}^{j p m} \leq(1-s) c_{2}^{j p m} Q_{2}^{j p m} \frac{\delta}{1-\delta}
$$

as $U 2$ 's punishment profit is zero. Adding up these incentive constraints, we obtain that collusion is a subgame perfect Nash equilibrium if and only if

$$
\pi_{2}^{m o n} \leq\left(c_{2}^{j p m} Q_{2}^{j p m}+p_{1}^{j p m} Q_{1}^{j p m}-\pi_{D 1}^{*}(0,0)\right) \frac{\delta}{1-\delta} .
$$

Solving for $\delta$ (and recalling $\pi^{j p m}=c_{2}^{j p m} Q_{2}^{j p m}+p_{1}^{j p m} Q_{1}^{j p m}$ ), we obtain the counterpart to Proposition 2:

Proposition 4 When $U 1$ and D1 are vertically integrated, collusion can be supported as a subgame perfect Nash equilibrium if only if

$$
\delta \geq \frac{\pi_{2}^{m o n}}{\pi_{2}^{m o n}+\pi^{j p m}-\pi_{D 1}^{*}(0,0)}
$$


Underlying Proposition 4 is the assumption that firms choose market shares such that the joint incentives to deviate are minimized. When the actual discount factor is higher than the threshold in Proposition 4, different markets shares become feasible. When the actual discount factor is equal to the threshold, we can substitute $\delta=\pi_{2}^{m o n} /\left(\pi_{2}^{m o n}+\pi^{j p m}-\pi_{D 1}^{*}(0,0)\right)$ back into either (10) or (11) (which hold with equality in this case) and solve for optimal market shares:

$$
s^{*}=\frac{c_{2}^{j p m} Q_{2}^{j p m}\left(\pi^{j p m}-\pi_{D 1}^{*}(0,0)\right)-\pi_{2}^{m o n}\left(p_{1}^{j p m} Q_{1}^{j p m}-\pi_{D 1}^{*}(0,0)\right)}{c_{2}^{j p m} Q_{2}^{j p m}\left(\pi_{2}^{m o n}+\pi^{j p m}-\pi_{D 1}^{*}(0,0)\right)} .
$$

It is straightforward to show $s^{*}<1$. A sufficient condition for $s^{*}>0$ is $c_{2}^{j p m} Q_{2}^{j p m}>\pi_{2}^{m o n}$ which holds with linear demand (see Appendix B). If a case can be made for $s^{*}<0$ (which the general model does allow for), this would amount to side payments from $U 1-D 1$ to $U 2$.

\section{The impact of vertical integration in a separated industry}

\subsection{Vertical integration facilitates upstream collusion}

We now turn to a key point of the analysis, the comparison of the minimum discount factor with and without vertical integration. From Proposition 2, we know that collusion can be supported as a subgame perfect Nash equilibrium in the separated industry if and only if $\delta \geq 1 / 2$. Comparing this constraint to the threshold in Proposition 4, collusion after the $U 1-D 1$ merger requires a discount factor smaller than $1 / 2$ if and only if

$$
\pi_{2}^{m o n}<\pi^{j p m}-\pi_{D 1}^{*}(0,0)
$$

This inequality follows from $\pi_{2}^{m o n}+\pi_{D 1}^{*}(0,0)<\pi_{2}^{m o n}+\pi_{D 1}^{*}\left(c_{2}^{m o n}, 0\right) \leq \pi^{j p m}$, where the strict inequality is due to the raising-rival's-costs effect (2) and the weak inequality follows by definition.

Proposition 5 The U1-D1 merger facilitates upstream collusion.

When $U 1$ and $D 1$ are integrated, collusion can be sustained as a subgame perfect Nash equilibrium for strictly lower discount factors compared to the $\delta=1 / 2$ benchmark of vertical separation. 
That is, in a vertical non-integrated industry, a vertical merger would facilitate collusion. Proposition 1 states that the vertical merger does not have any impact in the static game. By contrast, Proposition 5 shows that it does have an anticompetitive effect in the repeated game.

\subsection{Discussion and comparison with Nocke and White (2007)}

Nocke and White (2007) find a result identical to Proposition 5 for the case of two-part tariffs. Even though the main findings of Nocke and White and this paper are the same regardless of the contractual arrangements, there are several differences. This section discusses some of these differences. Nocke and White identify several effects of the vertical merger on upstream collusion. This section also contains a discussion of these effects.

Nocke and White essentially proceed as follows. Because there are two-part tariffs in their model, the upstream firms can earn maximum industry profits both with and without the vertical integration (provided the discount factor is sufficiently high). The upstream firms charge a wholesale price per unit for the input such that it is a best reply for the downstream firms to charge industry-profit-maximizing prices, and the profit the downstream firms make is then transferred back to the upstream firms with the help of the fixed fee. The industry-profit-maximizing prices (upstream and downstream) are, of course, the same either with or without the vertical merger, and the downstream market is symmetric in both cases.

With linear contracts, the analysis is somewhat different. To begin with, the colluding upstream firms can never earn maximum industry profits because there will be double marginalization for at least one downstream firm. More importantly, when $U 1$ and $D 1$ are integrated, $D 1$ obtains the input at marginal costs but $D 2$ pays a price above marginal cost. When upstream collusion is successful in the separated industry, both downstream firms pay a price above marginal cost. It follows that prices and profits are different in the two cases. Also, the downstream segment is asymmetric because of the raising-rivals'-costs effect when $U 1$ and $D 1$ are integrated, whereas, in the case of vertical separation, there is symmetry at the downstream level.

A first consequence of these differences is that, even though the main result is the same in both papers (the $U 1-D 1$ merger facilitates collusion), there is a subtle difference in the interpretation of the result. Because the colluding upstream firms may earn maximum industry profits both with and without the vertical merger, Nocke and White can focus on a ceteris paribus comparison of the critical discount factor required to sustain the industry profit maximum. Their main result 
(Proposition 1) means that the critical discount factor required to sustain the industry profit maximum is lower when one upstream firm is vertically integrated. In this paper, profits differ depending on whether or not $U 1$ and $D 1$ are integrated. Thus the comparison of discount factors cannot be made for equal profits. Here, the analysis focusses on the collusive equilibrium that requires the lowest discount factor in either case. The interpretation of the main result of this paper is that there exists a range of discount factors where the vertically integrated industry is collusive but the separated industry is not.

The differences between linear and two-part tariffs are also important when it comes to the various effects of vertical mergers on upstream collusion Nocke and White identify. Nocke and White show how firms in an unintegrated industry are affected by the $U 1-D 1$ merger, depending on whether they will be the integrated firm after the merger has taken place. To do this, they fix the share of the (symmetric) industry profit maximum each firm has and then check how the vertical merger changes the incentive constraint (3), provided that exactly the same outcome (in terms prices and shares of the profits) are realized after the merger. As already noted, we need to analyze the impact of vertical integration by comparing across different outcomes in this paper. Moreover, we need new notation for shares of the collusive profits here because markets shares in the external input market, $s$, and shares of the collusive profit differ. $D 1$ 's profit is part of the collusive profit, but it cannot be transferred to $U 2$ (neither in equilibrium nor in the case of a U2 deviation). ${ }^{12}$ By contrast, in the separated industry, market shares and shares of the collusive profits are identical (see Section 4), as in Nocke and White.

Therefore, we introduce the variable $r$ which denotes $U 1-D 1$ 's share of the collusive profit, and $1-r$ is $U 2$ 's share, accordingly. The market share variable $s$ relates to $r$ in that

$$
r=\frac{p_{1}^{j p m} Q_{1}^{j p m}+s c_{2}^{j p m} Q_{2}^{j p m}}{p_{1}^{j p m} Q_{1}^{j p m}+c_{2}^{j p m} Q_{2}^{j p m}}
$$

with $U 1-D 1$ integration.

The $r$ variable allows us to investigate the effects of the vertical integration as in Nocke and White. For $U 1-D 1,(4)$ becomes

$$
\delta_{U 1-D 1}=\frac{(1-r) \pi^{j p m}}{\pi^{j p m}-\pi_{D 1}^{*}(0,0)}>1-r
$$

\footnotetext{
${ }^{12}$ Even if we allow $D 1$ to procure from $U 2$ (which, as noted above, amounts to allowing side payments) and even if, in addition, we define market shares such that they include both the external input market plus the internal $U 1-D 1$ transfer, these redefined input market shares still do not directly correspond to shares of the collusive profits because of the downstream asymmetry. One unit of input sold by $D 2$ yields a collusive profit of $c_{2}$ whereas one sold by $D 1$ yields $p_{1}$.
} 
where the inequality is due to $\pi_{D 1}^{*}(0,0)>0$ and where $1-r(=1-s)$ is the benchmark of the separated industry (see (5)). That is, when we compare a separated and an integrated firm which get an identical share of the collusive industry profits, $r$, the minimum discount factor for the integrated firm is higher. Nocke and White (2007) call this the punishment effect. The punishment effect occurs because the integrated firm makes a positive profit in the static Nash equilibrium $\left(\pi_{D 1}^{*}(0,0)>0\right)$ whereas a non-integrated firm makes no profit in the static Nash equilibrium. As in Nocke and White (2007), the punishment is less harsh for an integrated firm which, all else equal, makes collusion more difficult to sustain.

For $U 2$, equation (4), the condition for collusion to be feasible, becomes

$$
\delta_{U 2}=\frac{\pi_{2}^{\text {mon }}-(1-r) \pi^{j p m}}{\pi_{2}^{\text {mon }}}<r
$$

where the inequality is due to $\pi_{2}^{m o n}<\pi^{j p m}$ and where $r(=s)$ is the benchmark of the separated industry (see (6)). There are two effects here, both of which can also be found in Nocke and White $(2007)$.

The outlets effect arises from the fact that the non-integrated upstream firm cannot sell to the downstream affiliate of the integrated rival when deviating. Specifically, D1's profit is part of the collusive profit but it cannot be seized by $U 2$ through a deviation. ${ }^{13}$ This effectively curbs $U 2$ 's deviation profits compared to the separated industry where $U 2$ can obtain 100 percent of the collusive profits when deviating. All else equal, lower deviation profits imply a lower minimum discount factor.

The reaction effect arises because $U 1-D 1$ can observe if $U 2$ deviates at the upstream level and can adapt its downstream price accordingly (see also the analysis of downstream pricing in Lemma 1 in Appendix A). The reaction effect reduces $U 2$ 's deviation profits compared to the separated case where downstream pricing is unaffected by upstream deviations. This implies a further reduction of the minimum discount factor. ${ }^{14}$

\footnotetext{
${ }^{13} U 2$ cannot sell to $D 1$ in equilibrium either (by assumption), but crucial for the outlets effect is that $D 1$ would never buy from $U 2$ after a $U 2$ deviation.

${ }^{14}$ One can hypothetically isolate the outlets effect from the reaction effect by assuming that downstream firms cannot react to any upstream deviation. Suppose that $D 1$ and $D 2$ stick to the equilibrium downstream prices $p_{1}^{j p m}$ and $p_{2}\left(c_{2}^{j p m}\right)$ regardless of the price of the input. In that case $U 2$ would earn $c_{2}^{j p m} Q_{2}^{j p m}$ when deviating, but it cannot get $p_{1}^{j p m} Q_{1}^{j p m}$ due to the outlets effect. Note that $c_{2}^{j p m} Q_{2}^{j p m}<\pi^{j p m}=c_{2}^{j p m} Q_{2}^{j p m}+p_{1}^{j p m} Q_{1}^{j p m}$ and thus $\delta_{U 2}<r$. That is, even if there was no reaction effect, the outlets effect alone would reduce the minimum discount factor (as in Nocke and White, 2007). Another scenario where no reaction effect can occur is when downstream firms always charge the static Nash prices, regardless of the industry structure and nature of upstream competition. This scenario is analyzed in Section 6.6.
} 
The net impact of the punishment, the outlets and reaction effect is positive - otherwise, we would not have obtained the result that vertical integration facilitates collusion (Proposition 5). In other words, writing down the incentive constraints (3) with the help of the shares of collusive profits, $r$, and adding them up yields the constraint in Proposition 4 again.

Nocke and White (2007) also identify a lack-of-commitment effect. This effect does not occur in this model and it is easy to see why. In Nocke and White (2007), downstream prices are such that they maximize industry profits (that is, the sum $U 1-D 1, U 2$ and $D 2$ 's profits) when $U 1-D 1$ and U2 successfully collude. If the integrated firm deviates, however, it will choose a downstream price that maximizes its own profits and will thus choose a more competitive price at the downstream level. This will be anticipated by $D 2$ and thus $U 1-D 1$ cannot obtain maximum industry profits when deviating. This is the lack-of-commitment effect. In this model, the effect does not occur because upstream firms charge a linear price for the input and D2 makes a positive profit (which is not part of the collusive profits). $U 1-D 1$ and $U 2$ do not collude by maximizing industry profits. Instead, they collude by maximizing the joint profits of $U 1-D 1$ and $U 2$. When $U 1-D 1$ deviates, $U 2$ 's profit is zero and the entire upstream profit goes to $U 1-D 1$. Thus $U 1-D 1$ will set the same downstream price after it deviates and thus there is no lack-of-commitment effect.

Finally, Nocke and White (2007) suggest a market share motive for vertical merger. The logic behind this motive is that the integrated firm has an incentive to cheat unless it gets a market share larger than a symmetric division of the market implies. In a market without integration, the symmetric division of the market minimizes the critical discount factor. Thus, by vertically merging, the integrated firm can ensure itself a bigger market because otherwise collusion might break down. In the model of this paper, the integrated firm has a bigger market share, too. Because of the raising-rival's-costs effect and ex-ante symmetry, $D 1$ will always sell more than $D 2$. Thus, even in the case where $U 1-D 1$ does not sell any input at all on the external input market $(s=0)$, its overall market share including externally traded input and internal $U 1-D 1$ transfer (that is, $\left.Q_{1} /\left(Q_{1}+Q_{2}\right)\right)$ will be larger than a symmetric division of the market would suggest.

\subsection{Example with linear demand}

In order to illustrate some of the results derived above, consider the following parameterized version of the model, also used in OSS (1990), as an example. Demand is assumed to be linear, symmetric 
and the demand intercept is, without loss of generality, normalized to one

$$
Q_{i}\left(p_{i}, p_{j}\right)=1-b p_{i}+d\left(p_{j}-p_{i}\right), i, j,=1,2 ; i \neq j
$$

where $b, d \geq 0$. It simplifies the analysis to rewrite this as

$$
Q_{i}\left(p_{i}, p_{j}\right)=1-k p_{i}+d p_{j}, i, j,=1,2 ; i \neq j
$$

where $k=b+d$. Products are entirely independent if $d=0$ whereas $d \rightarrow \infty$ would imply perfectly homogenous goods. Di's profit is

$$
\pi_{D i}=\left(1-k p_{i}+d p_{j}\right)\left(p_{i}-c_{i}\right), i, j,=1,2 ; i \neq j
$$

In Appendix B, explicit solutions for $c_{2}^{j p m}, p_{1}^{j p m}$, the corresponding profit expressions and the minimum discount factors can be found. Appendix B also shows how $s$ is used to relax the incentive constraint as far as possible. The optimal $s$, denoted by $s^{*}$, is implicitly defined by $\delta_{U 1-D 1}(s)=\delta_{U 2}(s)$.

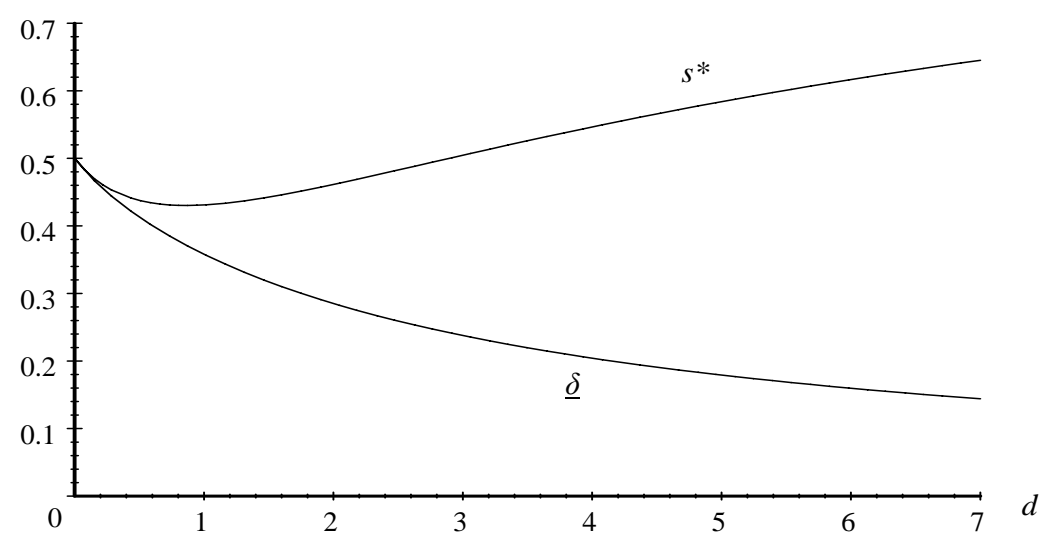

Figure 1. U1-D1's optimal market share, $s^{*}$, and the resulting minimum discount factor, $\underline{\delta}$, as a function of the degree of product differentiation, $d$ (where $k=d+1$ is w.l.o.g. regarding the qualitative properties of the figure.)

Using the closed-form solutions derived from the linear-demand model, Figure 1 plots $s^{*}$ and the resulting minimum discount factor $\underline{\delta}=\max \left\{\delta_{U 1-D 1}, \delta_{U 2}\right\}$ as a function of the parameter 
of product differentiation, $d$, where $\delta_{U 1-D 1}=\delta_{U 2}=\underline{\delta}$ if and only if $s=s^{*}$. We make three observations

- The Figure illustrates that the reduction of the minimum discount factor can be quantitatively substantial. $\underline{\delta}$ decreases monotonically in $d$. Using the algebra in Appendix B, we can also take $\lim _{d \rightarrow \infty}$. In that case, we obtain $s=1$ and $\underline{\delta}=0$. With vertical separation, the minimum discount factor required for collusion is $1 / 2$ regardless of the degree of product differentiation.

$-s^{*}$ is non-monotonic in the parameter of product differentiation, $d$, and has a minimum smaller than $1 / 2$.

- If $d=0$, we have $s=\underline{\delta}=1 / 2$. This is intuitive because, when products are entirely independent, raising $D 2$ 's cost does not improve $D 1$ 's profit and so firms face the same incentives as in the separated industry.

\subsection{Extension to bilateral oligopoly}

It is relatively straightforward to see that Proposition 5 also holds with more than two upstream firms. Suppose there are $n>2$ upstream firms, one of which is vertically integrated, say $U 1-D 1$. The prices that maximize the joint-profits of the colluding firms $(U 1-D 1, U 2, \ldots, U n)$ do not change

since the upstream firms have the same constant marginal costs. Thus, $c_{2}^{j p m}$ and $p_{1}^{j p m}$ maximize the joint profits as in Proposition 5 for the duopoly case. What does change with $n>2$ is that the profit made in the input market is divided among more firms, so collusion will generally be more difficult. But, as we will see, collusion will still require a lower discount factor when one firm is vertically integrated.

In the separated industry, a symmetric division of the market minimizes the critical discount factor. In that case, each upstream firm has a minimum discount factor of $\delta_{U i}=(n-1) / n$, $i=1, \ldots, n$.

When $U 1$ and $D 1$ are vertically integrated, assume as above that the integrated firm has a market share of $s$ and the $n-1$ non-integrated firms symmetrically split the rest so that each has a share of $(1-s) /(n-1)$. If firms collude by charging $c_{2}^{j p m}$ and $p_{1}^{j p m}, U 1-D 1$ 's incentive constraint 
is

$$
(1-s) c_{2}^{j p m} Q_{2}^{j p m} \leq\left(p_{1}^{j p m} Q_{1}^{j p m}+s c_{2}^{j p m} Q_{2}^{j p m}-\pi_{D 1}^{*}(0,0)\right) \frac{\delta}{1-\delta}
$$

as in the duopoly case. For each of the $n-1$ non-integrated upstream firms $U 2, \ldots, U n,(3)$ becomes

$$
\pi_{2}^{m o n}-\left(\frac{1-s}{n-1}\right) c_{2}^{j p m} Q_{2}^{j p m} \leq\left(\frac{1-s}{n-1}\right) c_{2}^{j p m} Q_{2}^{j p m} \frac{\delta}{1-\delta}
$$

Adding up these $n$ incentive constraints and solving for $\delta$, we obtain

$$
(n-1) \pi_{2}^{m o n} \leq\left(p_{1}^{j p m} Q_{1}^{j p m}+c_{2}^{j p m} Q_{2}^{j p m}-\pi_{D 1}^{*}(0,0)\right) \frac{\delta}{1-\delta} .
$$

Comparing this constraint to the threshold obtained with vertical separation, $(n-1) / n$, collusion requires a discount factor lower if and only if $\pi_{2}^{m o n}<\pi^{j p m}-\pi_{D 1}^{*}(0,0)$. We know from the analysis of the duopoly case that this condition holds (see (14)). Thus, vertical integration facilitates collusion also with $n>2$ upstream firms.

The results do not change qualitatively either when there are $m>2$ downstream firms. To begin with, note that raising one downstream firm's cost has similar qualitative effects to raising two or more downstream firms' costs. Further, what matters are the market shares $s$ and $1-s$ the upstream firms have in the input market. For $m=2$, industry profits in the external input market are $c\left(Q_{1}+Q_{2}\right)$ and $c_{2} Q_{2}$ with vertical separation and integration, respectively. This can be extended for $Q_{3}, \ldots, Q_{m}$ for the $m>2$ case. Because the downstream markets are symmetric, we have $Q_{2}=Q_{3}=\ldots=Q_{m}$. Thus, some $\tilde{Q}=(m-1) Q_{2}$ can be thought of as representing the sales of all non-integrated downstream firms. But when using the $\tilde{Q}$ aggregate measure, the analysis is the same as the analysis of downstream duopoly above. Whether it is one or more non-integrated downstream firms purchasing on the input market is therefore immaterial and, thus, does not change the results qualitatively. ${ }^{15}$

\subsection{Welfare}

This Section discusses the welfare implications of the results. To prepare the welfare analysis, it is useful to make the notion that vertical integration facilitates collusion more precise. A collusive

\footnotetext{
${ }^{15}$ It is not possible to make a statement about the quantitative effects of having $m>2$ downstream firms without making further specific modeling assumptions. It does seem intuitive, though, that the larger the number of downstream firms, the more significant the upstream collusive profit $c_{2} \tilde{Q}$ will be compared to the collusive downstream profit, $\pi_{D} 1$. Nevertheless, the punishment, outlets and reaction effect will be present even when $\pi_{D} 1$ is negligible compared to the upstream collusive profit.
} 
effect of the $U 1-D 1$ merger occurs for an intermediate range of minimum discount factors. For low values of $\delta$ (precisely, for $\delta<\underline{\delta}<1 / 2$ ), neither the integrated nor the separated industry is collusive. For $\delta \geq 1 / 2$, both the integrated and non-integrated structure will be collusive. It is for the range of intermediate discount factors $\underline{\delta} \leq \delta<1 / 2$ where the industry is collusive only with the $U 1-D 1$ merger, but not when firms are vertically separated. If firms' actual discount factor is in this range, vertical integration will cause an increase of the input price.

This does, however, not imply that vertical integration is unambiguously bad for welfare. Economic welfare will not be affected in the case of low discount factors, and it will be affected negatively by a vertical merger in the intermediate case where only the integrated industry is collusive. However, in the case where both separated and integrated industries are collusive, vertical integration may also have positive welfare effects. With integration, only the non-integrated downstream firm pays a collusive price for the input, whereas the integrated downstream firm receives the input internally (and efficiently) at marginal cost. Without the vertical merger, both downstream firms pay a collusive input price above marginal cost. As vertical integration implies that the double markup for the integrated downstream firm is eliminated, the welfare balance of vertical integration might be positive if both separated and integrated industries are collusive. Thus, the overall the welfare effects of vertical integration are ambiguous. This is in contrast to Nocke and White's (2007) analysis where the vertical merger implies a negative change in welfare.

Proposition 6 The welfare effects of the U1-D1 merger are ambiguous.

The linear demand example can be used to illustrate some welfare-related issues for the $\delta \geq 1 / 2$ case when collusion is feasible in either case. With linear demand, we can contrast the equilibrium described in Proposition 3 to the scenario where separated upstream firms maximize their joint profits. Compared to the collusive separated industry, collusion with a single firm integrated causes a lower price for the input. ${ }^{16}$ That is, D2 purchases the input at a lower price with vertical integration and the effective price for $D 1$ is $c_{1}=0$ with $U 1-D 1$ integration anyway. This shows how vertical integration may improve welfare.

\footnotetext{
${ }^{16}$ Using the closed-form solutions for downstream outputs in (47), the upstream profits of vertically separated firms are $2 c k(1-c(k-d)) /(2 k-d)$ if $c_{1}=c_{2}=c$. The price maximizing this profit is $c=1 /(2(k-d))$. It is easy to show that this price is larger than $c_{2}^{j p m}$ as in (39).
} 
A second point which can be illustrated with the linear demand when $\delta \geq 1 / 2$. Suppose the separated $U 1$ and $U 2$ collude successfully. By merging, $U 1-D 1$ and $U 2$ can increase their joint profit. However, $U 2$ 's stand-alone profit decreases when $U 1$ and $D 1$ merge. This is the case even with $s=0$ where $U 2$ gets $100 \%$ of the upstream profit. ${ }^{17}$ That is, absent side payments, $U 2$ strictly loses from the vertical merger. Thus, when successful collusion of the separated industry is the status quo, $U 2$ would not support the $U 1-D 1$ merger. It is difficult to see how $U 2$ would peacefully agree to price agreements following a merger that reduces its profits strictly (for example, $U 2$ might threat to commit itself to competitive pricing if the vertical merger is carried out). This result may indicate that a $U 1-D 1$ merger is unlikely to occur when $\delta \geq 1 / 2$. In turn, this would imply that, if $U 1$ and $D 1$ merge, the vertical integration is likely to be anti-competitive.

\section{6 $\quad D 1$ as a profit center}

In this Section, we will analyze the special case where the downstream price of the integrated firm, $p_{1}$, maximizes the short-run profits of $D 1$ rather than $U 1-D 1$ 's profits or $U 1-D 1$ and $U 2$ 's joint profits. We know from Proposition 3 that such behavior is not optimal and thus must increase the critical discount factor. However, myopic profit-maximizing behavior is plausible when $D 1$ operates as a profit center. Beyond any interest in the specific profit center case (see, e.g., Radner and Ichiishi, 1999), a general motivation for this analysis is that downstream pricing will be exactly as in the static model of OSS (1990) under this assumption. That is, we can analyze the behavior of the upstream firms in the repeated game given the same downstream Nash prices as in the static game. Thus, this exercise can add further insight how vertical mergers change the incentives for competition in the input market.

For the ease of presentation, assume further that $U 1-D 1$ and $U 2$ charge the monopoly price in (9) for the input. ${ }^{18}$ As above, $D 1$ obtains the input at marginal cost $c_{1}=0$. That is, we have $c_{2}=c_{2}^{m o n}, p_{1}=p_{1}^{*}\left(0, c_{2}^{m o n}\right)$ and $p_{2}=p_{2}^{*}\left(c_{2}^{m o n}, 0\right)$ throughout Section 6.6.

Under these assumptions, we analyze the incentives for collusion again. Consider collusive profits, $\pi_{i}^{c}$, first. At the upstream level, $U 1-D 1$ makes a profit of $s \pi^{m o n}$. At the downstream level,

\footnotetext{
${ }^{17}$ With $c=1 /(2(k-d))$, the resulting maximum upstream profit of the separated $U 1$ and $U 2$ is $k /(2(2 k-d)(k-d))$. With $s=1 / 2$ before the merger, $U 2$ gets $k /(4(2 k-d)(k-d))>c_{2}^{j p m} Q_{2}^{j p m}$. Thus, even if $s=0$ after the merger, $U 2$ strictly loses profits from the merger.

${ }^{18}$ A previous version of the paper, Normann (2004), treats the profit center case more extensively. The assumption $c_{2}=c_{2}^{m o n}$ is without loss of generality in that, for part (i) of Proposition below to hold, it is sufficient to show that it holds for one level of $c_{2}$. Part (ii) generally holds for any level of $c_{2}$.
} 
$U 1-D 1$ makes a profit of $\pi_{D 1}^{*}\left(0, c_{2}^{m o n}\right)$. Therefore, $\pi_{1}^{c}=s \pi^{m o n}+\pi_{D 1}^{*}\left(0, c_{2}^{m o n}\right) . U 2$ makes a collusive profit of $\pi_{2}^{c}=(1-s) \pi^{m o n}$. When defecting, either firm will undercut $c_{2}^{m o n}$ by an infinitesimally small margin and will obtain $\pi^{m o n}$ in the period of defection. It follows that $\pi_{1}^{d}=\pi^{m o n}+\pi_{D 1}^{*}\left(0, c_{2}^{m o n}\right)$ and $\pi_{2}^{d}=\pi^{m o n}$. Punishment (Nash) profits are $\pi_{1}^{p}=\pi_{D 1}^{*}(0,0)$ and $\pi_{2}^{p}=0$.

Using these expressions and plugging them into (4), the minimum discount factors after the $U 1-D 1$ integration are

$$
\delta_{U 1-D 1}=\frac{(1-s) \pi^{m o n}}{\pi^{m o n}+\pi_{D 1}^{*}\left(0, c_{2}^{m o n}\right)-\pi_{D 1}^{*}(0,0)}<1-s
$$

where the inequality is due to $\pi_{D 1}^{*}\left(0, c_{2}^{m o n}\right)-\pi_{D 1}^{*}(0,0)>0$, and

$$
\delta_{U 2}=\frac{\pi^{m o n}-(1-s) \pi^{m o n}}{\pi^{m o n}}=s .
$$

We obtain $\delta_{1}+\delta_{2}<1$. Therefore, suitable values of $s$ push both minimum discount factors below $1 / 2$.

We conclude that collusion when $U 1$ and $D 1$ are integrated also requires a lower discount factor than upstream collusion with vertical separation when we impose the above assumptions. That is, even when $D 1$ operates as a profit center and when it is thus not involved in the collusion, we still obtain the crucial result that vertical integration facilitates collusion. The reaction effect discussed above cannot occur in this case and is therefore not necessary to obtain the main result. Nocke and White (2007) also note that their main result does not require a reaction effect.

The profit center assumption also helps to clarify another important issue. In OSS (1990), vertical mergers are connected with a notion of foreclosure. The integrated firm is supposed to withdraw from the input market. ${ }^{19}$ By contrast, the integrated firm is active in the input market in the present model. Moreover, Figure 1 shows that $U 1-D 1$ 's market share is always positive and can be even larger than 50\%. That is, the analysis so far has not been supportive of OSS' (1990) idea of foreclosure.

If $D 1$ is a profit center, the case for foreclosure in OSS' (1990) sense is stronger. We can interpret the market share of the integrated firm, $s$, as an indicator of foreclosure in that $s=0$ would correspond to the case where $U 1-D 1$ completely withdraws from the input market. Similarly, market outcomes with $s<1 / 2$ can be interpreted as a partial "withdrawal" because $U 1-D 1$ 's

\footnotetext{
${ }^{19}$ OSS' (1990) notion of foreclosure differs from the one by Rey and Tirole (2007) who define foreclosure more broadly as the denial of complete access of downstream competitors to the input good.
} 
market share is less than a symmetric division of the market would suggest. ${ }^{20}$

Bearing this notion of foreclosure in mind, it is easy to see that $s<1 / 2$ is actually crucial when $U 1$ and $D 1$ are integrated and given the profit center assumption. (Recall that the market shares $s$ and $-1 s$ refer to the external market.) We have $\delta_{U 1-D 1}<1-s$ and $\delta_{U 2}=s$ in (16) and (17). It follows that, $s<1 / 2$ is a necessary condition when firms look for the collusive equilibrium with the lowest discount factor. Given the profit center assumption, the vertical merger facilitates collusion if and only if $s<1 / 2$ because $s>1 / 2$ would imply $\delta_{2}>1 / 2 \cdot{ }^{21}$ We summarize:

Proposition 7 Assuming $c_{2}=c_{2}^{\text {mon }}$ and $p_{1}=p_{1}^{*}\left(0, c_{2}^{m o n}\right)$, we obtain the following results. (i) The U1-D1 merger facilitates collusion. (ii) With U1-D1 integration, foreclosure $(s<1 / 2)$ is necessary to obtain a minimum discount factor of less than 1/2.

\section{$7 \quad$ Alternative scenarios}

\section{1 $U 2-D 2$ Counter merger}

OSS (1990) argue that $U 2$ and $D 2$ have an incentive for counter merger after $U 1$ and $D 1$ integrate. They show that $U 2$ and $D 2$ can increase their joint profits by vertically integrating (and, in turn, supplying $D 2$ internally at marginal cost) compared to the case where $U 2$ charges the monopoly price for the input. This implies $U 1-D 1$ has to limit the price of the input below $U 2$ 's monopoly price in order to prevent the counter merger from happening. One of OSS' (1990) key results is that the counter merger can always be prevented in this manner since the joint profits of $U 2$ and $D 2$ turn out to be higher for some small positive value of $c_{2}$ compared to their joint profits after the vertical merger. Formally, the highest price that will deter the counter merger is implicitly defined by $c_{2}^{*}:=\left\{c_{2} \mid \pi_{D 2}^{*}\left(c_{2}, 0\right)+c_{2} Q_{2}^{*}\left(c_{2}, 0\right)=\pi_{D 2}^{*}(0,0)\right\}$ (see OSS, 1990, p. 141). We need to check whether the $U 1-D 1$ merger may provoke a counter merger in a similar way in the repeated-game setting of this paper. As in OSS (1990), it is useful to apply the parameterized model with linear demand here.

\footnotetext{
${ }^{20}$ While it can be observed whether or not $U 1-D 1$ has a market share in the external input market of less than 50 percent after the merger, it depends on the pre-merger market shares whether this implies a decrease or an increase of $U 1-D 1$ 's market share. Thus, observed changes in market share may not unambiguously identify foreclosure.

${ }^{21}$ This condition is not restricted to the $c_{2}=c_{2}^{m o n}$ case; it is a general requirement. It is straightforward to see that $c_{2}=c_{2}^{\text {mon }}$ minimizes $\delta_{2}$ for any $s$. Thus, we obtain $\delta_{2} \geq\left.\delta_{2}\right|_{c=c_{2}^{m o n}}=s$ and therefore $\delta_{2}<1 / 2$ only if $s<1 / 2$.
} 
Assuming there is a counter-merger threat in the setup of this paper, one thing to check is whether the joint-profit maximizing prices, $c_{2}^{j p m}$ and $p_{1}^{j p m}$, together with the optimal market shares $\left(s^{*}, 1-s^{*}\right)$ are suitable to prevent the counter merger. It turns out that this is not the case. At the joint-profit-maximizing prices, the counter merger does pay (see Appendix C). Thus, the collusive equilibrium that minimizes the critical discount factor is not tenable when $U 2$ and $D 2$ can merge.

A second step would be to ask whether the counter merger can be prevented at all. Here, the answer is affirmative and this is hardly surprising given that OSS (1990) have shown this result already in the static game (and for a scenario corresponding to $s=0$ and $p_{1}=p_{1}^{*}$ ). Indeed, the incentive for counter merger is weaker in this model than in OSS (1990) as $U 1-D 1$ charges a higher downstream price than in the static game. All else equal, this raises D2's and U2's profits and thus makes the $U 2-D 2$ merger less attractive. As an example, Appendix $\mathrm{C}$ shows that $c_{2}=c_{2}^{*}$ (the input price OSS (1990) derive for the static game) and an appropriately chosen $s$ will prevent the counter merger.

Taking these two results together, it follows that setting prices and market shares in order to prevent the counter merger comes at a cost. The profitability of collusion declines as the input price possibly has to be set below $c_{2}^{j p m}$, and if prices and market shares are not set as in Proposition 3 the minimum discount factor will also increase. While it is not possible to solve explicitly for the collusive equilibrium that minimizes the critical discount factor and prevents the counter merger, one can derive examples where the minimum discount factor is below the threshold of $1 / 2$ and no incentive for counter merger exists. Generally, the counter merger is beneficial from a welfare perspective.

\subsection{Downstream collusion}

So far, the analysis has been on upstream collusion, but there may also be the possibility of downstream collusion. If downstream collusion is possible, this could challenge the above results. Possibly, $D 1$ prefers to collude with $D 2$ and thus would not want to merge with $U 1$.

Appendix D analyzes downstream collusion with linear demand (see, for example, Deneckere, 1983). Two results derive from this example. First, downstream firms can largely eliminate the temptation to deviate. More precisely, by choosing collusive prices close to static Nash equilibrium prices, $D 1$ and $D 2$ can lower the minimum discount factor required for collusion arbitrarily close to 
zero. The intuition is that deviation profits increase more quickly in the collusive prices than the corresponding collusive profit, so higher collusive prices require a higher minimum discount factor. When prices are close to the static Nash level, the incentive to deviate is negligible. This implies that some downstream collusion is always feasible, no matter how low the actual discount factor is. This is an advantage compared to upstream collusion after the $U 1-D 1$ merger which requires a strictly positive minimum discount factor (as it is not an equilibrium in the static game). The second result is that downstream collusion can yield maximum industry profits, provided there is upstream competition (such that $c_{1}=c_{2}=0$ ) and the discount factor is sufficiently high. This is not possible with upstream collusion, either with or without vertical integration, as there will always be double marginalization for at least one firm. Thus, downstream collusion seems advantageous as it works even with rather low discount factors and it must eventually yield higher collusive profits when the actual discount factor is sufficiently high.

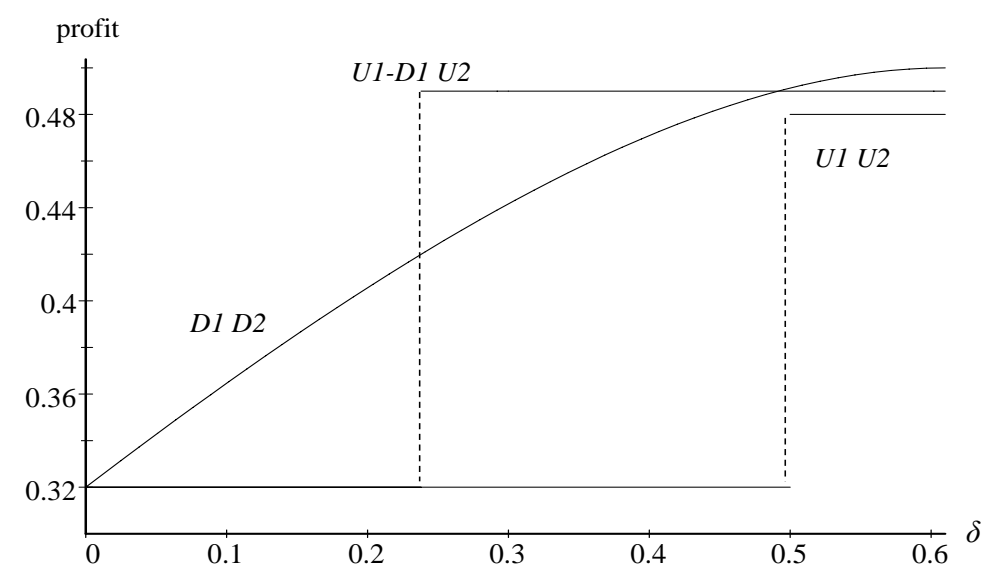

Figure 2. Industry profits as a function of the discount factor for three collusion scenarios: upstream collusion with vertical separation ( $U 1 \mathrm{U} 2)$, upstream collusion with vertical integration (U1-D1 U2) and downstream collusion (D1 D2). The example is based on the linear demand model, $k=d+1$ and $d=3$. In the static Nash equilibrium, industry profits are 0.32 ; maximum industry profits are 0.5 .

However, the analysis of the linear demand model also shows that upstream collusion, when one firm is vertically integrated, may be more effective than downstream collusion, in the sense of yielding higher profits for comparable minimum discount factors. This is the case for certain 
degrees of product differentiation and some intermediate level of discount factors as illustrated in Figure 2. The Figure plots industry profits as a function of the discount factor for three collusion scenarios; upstream collusion of vertically separated firms ("U1 $U 2$ "), upstream collusion when $U 1-D 1$ are integrated (" $U 1-D 1 U 2$ "), and downstream collusion of vertically separated firms ("D1 D2"). ${ }^{22}$ In all three cases, industry profits are 0.32 if the discount factor is zero (this is the static Nash profit of the two downstream firms in this example; the upstream firms make a static Nash profit of zero). Higher discount factors make collusion and therefore higher profits feasible. From the analysis above, we know about the two cases of upstream collusion. Upstream collusion with vertical separation $(U 1 U 2)$ is feasible only if $\delta \geq 1 / 2$. In that case, industry profits increase from 0.32 to 0.48 . Upstream collusion with vertical integration ( $U 1-D 1 U 2)$ requires a discount factor of 0.23 in the example, and if $\delta \geq 0.23$ industry profits of 0.49 result. Finally, with downstream collusion ( $D 1 D 2)$ (where firms are assumed to get the input at marginal cost), profits monotonically increase in $\delta$ until, with a discount factor of larger than 0.61 , the maximum industry profit of 0.5 results.

For $\delta \in[0.23,0.49]$, upstream collusion after the $U 1-D 1$ merger yields higher industry profits than downstream collusion. Importantly, not only are industry profits higher when $U 1-D 1$ and $U 2$ collude, but the joint profits of the colluding firms (U1-D1 U2) are also higher compared to $D 1-D 2$ collusion. This is perhaps not surprising, as $D 1$ 's profit is increased at $D 2$ 's expense, but this has an important implication. The result implies that $U 1$ and $D 1$ may have an incentive to merge even when downstream collusion is an option. ${ }^{23}$ In the example, this is the case when $\delta \in[0.23,0.49]$. The general conclusion is that the possibility of downstream collusion does not eliminate the incentive for vertical integration. ${ }^{24}$

\footnotetext{
${ }^{22}$ The Figure plots industry profits (the profits of $U 1, U 2, D 1$ and $D 2$ ) in all cases for the sake of comparability. While higher industry profits do not guarantee that the industry structure yielding those profits will also emerge endogenously from merger decisions (and vice versa), they are nevertheless a useful indicator. It is beyond the scope of this paper to present a model of endogenous mergers.

${ }^{23} \mathrm{As}$ an aside, note that when collusion is feasible at both upstream and downstream level, the integrated firm can choose at which level it prefers to collude, as it is always free to deny cooperation at one level and (tacitly) agree to cooperate at the other level.

${ }^{24}$ In contrast to the example in Figure 2, there are also cases where downstream collusion is more effective than upstream collusion with vertical integration. For example, when products are rather heterogenous, downstream collusion amounts to two nearly independent monopolies and thus yields almost maximum industry profits even with very low discount factors. By contrast, upstream collusion with vertical integration cannot yield maximum industry profits because of the double markup.
} 


\section{Conclusion}

This paper analyzes upstream collusion in the presence of a vertically integrated firm when downstream firms pay a linear price for the input. In the model, the downstream unit of the integrated firm benefits from a raising-rivals'-costs effect when the input market is collusive. While this raising-rivals'-costs strategy (OSS, 1990) is not an equilibrium in the static game (Hart and Tirole, 1990; Reiffen, 1992), this paper shows that it is a subgame perfect Nash equilibrium in the repeated game.

A central result of the paper is that, in a separated industry, a single vertical merger facilitates upstream collusion, that is, it causes a reduction of the minimum discount factor required for collusion. Thus, firms have an incentive for anticompetitive vertical merger. This complements the analysis of Nocke and White (2007) who prove the same result in a model with two-part tariffs. Interestingly, the effects underlying this result (punishment, outlets and reaction effect) turn out to be work rather similarly with linear prices and two-part tariffs. In contrast to the two-part tariffs model, however, the overall welfare balance of vertical integration is not necessarily negative with linear tariffs. The integrated firm delivers its downstream unit at marginal cost, and this elimination of a double markup can imply a welfare gain compared to the case where vertically separated firms collude. Alternative scenarios, including counter merger and downstream collusion, do not generally eliminate the incentive for vertical merger.

The paper further adds to the foreclosure debate (see, e.g., Riordan, 2008). When upstream firms successfully collude, they reduce demand as a function of the price. This would be foreclosure in the broad definition of Rey and Tirole (2007). They define any case where downstream firms have incomplete access to the input good as foreclosure. OSS (1990) suggest a more specific notion of foreclosure where the integrated firm withdraws from the input market. In the model of this paper, the integrated firm is active in the input market and its market share is always positive (in an example with linear demand, the market share can even plausibly be above $50 \%$ ), so this result does not support OSS' (1990) idea of foreclosure. When the downstream unit of the integrated firm operates as a profit center, the case for OSS-type foreclosure is stronger. In this case, the market share of the integrated firm is less than a symmetric market division would suggest. Thus, there is at least partial foreclosure. 


\section{Appendix}

\section{Appendix A: Proof of Proposition 3}

The following additional notation will be used throughout Appendix A. We need the downstream price that maximizes the joint profits of $U 1-D 1$ and $U 2$ for some given $c_{2}$. Formally,

$$
\widehat{p}_{1}\left(c_{2}\right):=\underset{p_{1}}{\arg \max } p_{1} Q_{1}\left(p_{1}, p_{2}\left(c_{2}\right)\right)+c_{2} Q_{2}\left(p_{2}\left(c_{2}\right), p_{1}\right) .
$$

The joint-profit maximizing prices $p_{1}^{j p m}$ and $c_{2}^{j p m}$ in (8) relate to $\widehat{p}_{1}$ in that $p_{1}^{j p m}=\widehat{p}_{1}\left(c_{2}^{j p m}\right)$. The proof of Proposition 3 is established in six steps.

Step 1: Best downstream response after an upstream deviation. When a firm deviates from the collusive upstream price, $c_{2}, U 1-D 1$ can respond to the deviation by charging a downstream price different from the collusive one. This is possible because either $U 1-D 1$ is the deviator itself or, if $U 2$ defects, $U 1-D 1$ can observe $U 2$ 's deviation. In order to analyze the profitability of deviations at the upstream level, we first need to know how $U 1-D 1$ best responds to them at the downstream level. After an upstream deviation in period $t$, the punishment will be triggered in $t+1$ regardless of the downstream price $U 1-D 1$ charges in $t$. Sequential rationality implies that $U 1-D 1$ will set its downstream price such as to maximize its short-run profits. Thus, $U 1-D 1$ will always play its best reply after an upstream deviation, but its best downstream reply following a defection will depend on whether $U 1-D 1$ itself or $U 2$ is the defector.

First, if $U 1-D 1$ deviates at the upstream level by charging some $c_{2}^{d}<c_{2}, U 1-D 1$ will capture the entire upstream profit in addition to its downstream profit. In that case, $U 2$ earns nothing and $U 1-D 1$ 's defection profit is equal to the joint profit of $U 1-D 1$ and $U 2$ which is maximized if and only if $p_{1}=\widehat{p}_{1}\left(c_{2}^{d}\right)$ where $\widehat{p}_{1}$ is as in (26). Hence, $\widehat{p}_{1}\left(c_{2}^{d}\right)$ is $U 1-D 1$ 's optimal downstream price in this case.

Second, if $U 2$ is the deviator at the upstream level and sets some $c_{2}^{d}<c_{2}, U 1-D 1$ does not gain any upstream profit. $U 1-D 1$ 's profit is now equal to $D 1$ 's stand-alone profit only which is maximized if and only if $p_{1}=p_{1}^{*}\left(c_{2}^{d}\right)$. (Recall that $p_{1}^{*}\left(c_{2}^{d}\right)$ is $D 1$ 's myopic best reply.) Thus, we have

Lemma 1 If U1-D1 defects by setting $c_{2}^{d}<c_{2}, U 1-D 1$ 's optimal price at the downstream level is $\widehat{p}_{1}\left(c_{2}^{d}\right)$. If $U 2$ defects by setting $c_{2}^{d}<c_{2}, U 1-D 1$ 's optimal price at the downstream level is $p_{1}^{*}\left(c_{2}^{d}\right)$. 
Note that $U 1-D 1$ will best respond at the downstream level in period $t$ only if there has been a defection at the upstream level in $t$ in the first place. If $U 1-D 1$ defects from the collusive $p_{1}$ even though both firms charge the equilibrium $c_{2}$ at the upstream level, the punishment will nevertheless be triggered in $t+1$. But if collusion breaks down in the next period anyway, $U 1-D 1$ can increase its defection profit by deviating from $c_{2}$ before deviating from $p_{1}$.

Step 2: Optimal deviation at the upstream level. If $U 1-D 1$ defects at the $U$ level, we know from Lemma 1 that it will charge $\widehat{p}_{1}\left(c_{2}^{d}\right)$ afterwards at the $D$ level. This implies that the highest defection profit $U 1-D 1$ can obtain occurs if $c_{2}=c_{2}^{j p m}$ as in (8). Since $U 1-D 1$ 's defection profit monotonically increases in $c_{2}$ as long as $c_{2} \leq c_{2}^{j p m}$, we conclude that $U 1-D 1$ 's optimal defection is $c_{2}-\varepsilon$ if $c_{2} \leq c_{2}^{j p m}$ and the optimal defection is $c_{2}^{j p m}$ if $c_{2}>c_{2}^{j p m}$, where $\varepsilon$ denotes an infinitesimally small margin.

If $U 2$ defects, we know from Lemma 1 that $U 1-D 1$ will set $p_{1}^{*}\left(c_{2}^{d}\right)$ at the $D$ level. With a downstream price of $p_{1}^{*}\left(c_{2}\right)$, the highest defection profit $U 2$ can obtain results when $U 2$ charges $c_{2}^{m o n}$ as in (9). Since $U 2$ 's profit monotonically increases in $c_{2}$ up to $c_{2}^{\text {mon }}, U 2$ 's optimal defection is $c_{2}-\varepsilon$ if $c_{2} \leq c_{2}^{m o n}$ and it is $c_{2}^{m o n}$ if $c_{2}>c_{2}^{m o n}$. Hence, we obtain

Lemma $2 U 1-D 1$ 's optimal upstream defection is $c_{2}^{d}=c_{2}-\varepsilon$ if $c_{2} \leq c_{2}^{j p m}$ and $c_{2}^{d}=c_{2}^{j p m}$ if $c_{2}>c_{2}^{j p m}$. U2's optimal upstream defection is $c_{2}^{d}=c_{2}-\varepsilon$ if $c_{2} \leq c_{2}^{m o n}$ and $c_{2}^{d}=c_{2}^{m o n}$ if $c_{2}>c_{2}^{m o n}$. when $U 1-D 1$ and $U 2$ deviate, respectively.

Step 3: Defection profits. We can use Lemmas 1 and 2 to derive the profits resulting from a deviation.

Lemma 3 Given a collusive upstream price of $c_{2}$, Lemmas 1 and 2 imply defection profits of

$$
\begin{aligned}
\pi_{1}^{d} & = \begin{cases}\pi^{j p m} & \text { if } c_{2}>c_{2}^{j p m} \\
\widehat{p}_{1}\left(c_{2}\right) Q_{1}\left(\widehat{p}_{1}\left(c_{2}\right), p_{2}\left(c_{2}\right)\right)+c_{2} Q_{2}\left(p_{2}\left(c_{2}\right), \widehat{p}_{1}\left(c_{2}\right)\right) & \text { if } c_{2} \leq c_{2}^{j p m}\end{cases} \\
\pi_{2}^{d} & = \begin{cases}\pi_{2}^{\text {mon }} & \text { if } c_{2}>c_{2}^{\text {mon }} \\
c_{2} Q_{2}^{*}\left(c_{2}, 0\right) & \text { if } c_{2} \leq c_{2}^{\text {mon }} .\end{cases}
\end{aligned}
$$

Step 4. Collusive downstream prices that minimizes the discount factor required for collusion. For some given collusive upstream price $c_{2}$, it is easy to see that the collusive downstream price 
that minimizes the discount factor required for collusion is $p_{1}=\widehat{p}_{1}\left(c_{2}\right)$. The intuition is that the defection profits stated in Lemma 3 do not depend on $p_{1}$. If neither defection nor punishment profits are affected by the collusive $p_{1}$, the incentive constraints are relaxed as far as possible when the collusive profits are maximized. This is the case if and only if $p_{1}=\widehat{p}_{1}\left(c_{2}\right)$.

To prove this claim, note that $U 1-D 1$ 's collusive profit is $p_{1} Q_{1}\left(p_{1}, p_{2}\left(c_{2}\right)\right)+s c_{2} Q_{2}\left(p_{2}\left(c_{2}\right), p_{1}\right)$. Plugging this expression for the collusive profit, its defection profit $\pi_{1}^{d}$, as in Lemma 3 , and the static Nash profit $\pi_{D 1}^{*}(0,0)$ into the incentive constraint (3), we obtain

$$
\pi_{1}^{d}-p_{1} Q_{1}(.)+s c_{2} Q_{2}(.) \leq\left(p_{1} Q_{1}(.)+s c_{2} Q_{2}(.)-\pi_{D 1}^{*}(0,0)\right) \frac{\delta}{1-\delta}
$$

for $U 1-D 1$. $U 2$ 's collusive profit is $(1-s) c_{2} Q_{2}\left(p_{2}\left(c_{2}\right), \widehat{p}_{1}\left(c_{2}\right)\right)$, its defection profit is $\pi_{2}^{d}$ as in Lemma 3 , and the static Nash profit is zero. Thus, (3) becomes

$$
\pi_{2}^{d}-(1-s) c_{2} Q_{2}\left(p_{2}\left(c_{2}\right), p_{1}\right) \leq(1-s) c_{2} Q_{2}\left(p_{2}\left(c_{2}\right), p_{1}\right) \frac{\delta}{1-\delta}
$$

for $U 2$. Adding up the incentive constraints and rearranging, we get

$$
\delta \geq \frac{\pi_{1}^{d}+\pi_{2}^{d}-\left(p_{1} Q_{1}\left(p_{1}, p_{2}\left(c_{2}\right)\right)+c_{2} Q_{2}\left(p_{2}\left(c_{2}\right), p_{1}\right)\right)}{\pi_{1}^{d}+\pi_{2}^{d}-\pi_{D 1}^{*}(0,0)} .
$$

Since the defection profits, $\pi_{i}^{d}$ (as in Lemma 3), do not depend on $p_{1}$, choosing $p_{1}$ to maximize $p_{1} Q_{1}\left(p_{1}, p_{2}\left(c_{2}\right)\right)+c_{2} Q_{2}\left(p_{2}\left(c_{2}\right), p_{1}\right)$ relaxes the incentive constraints as far as possible. This is the case if and only if $p_{1}=\widehat{p}_{1}\left(c_{2}\right)$. Since $\widehat{p}_{1}\left(c_{2}\right)$ also maximizes collusive profits (for any $c_{2}$ ), it is optimal also when the incentive constraint is not binding. Thus, we have established

Lemma 4 Given some collusive upstream price $c_{2}$, the collusive downstream price that minimizes the discount factor required for collusion is $\widehat{p}_{1}\left(c_{2}\right)$.

Step 5: Collusive upstream price that minimizes the discount factor required for collusion.

Lemma 5 The collusive upstream price that minimizes the discount factor required for collusion is $c_{2}=c_{2}^{j p m}$.

From Lemma 3, optimal defection strategies of the upstream firms will differ depending on $c_{2}$. We need to distinguish between three parameter regions: (i) $c_{2} \geq c_{2}^{j p m}$, (ii) $c_{2}^{m o n} \leq c_{2}<c_{2}^{j p m}$, and 
(iii) $c_{2}<c_{2}^{\text {mon }}$. We need to consider optimal upstream pricing in each of these three regions in order to conclude the overall optimal price.

(i) If $c_{2} \geq c_{2}^{j p m}$, Lemma 4 implies a collusive profit of $\widehat{p}_{1} Q_{1}\left(\widehat{p}_{1}\left(c_{2}\right), p_{2}\left(c_{2}\right)\right)+s c_{2} Q_{2}\left(p_{2}\left(c_{2}\right), \widehat{p}_{1}\left(c_{2}\right)\right)$ for $U 1-D 1$ and Lemma 3 implies a defection profit of $\pi^{j p m}$ for $U 1-D 1$. For $U 2$, we obtain a collusive profit of $(1-s) c_{2} Q_{2}\left(p_{2}\left(c_{2}\right), \widehat{p}_{1}\left(c_{2}\right)\right)$ and a defection profit of $\pi_{2}^{m o n}$. Punishment profits are $\pi_{D 1}^{*}(0,0)$ and zero for $U 1-D 1$ and $U 2$, respectively. Adding up the incentive constraints, (3) yields

$$
\pi^{j p m}+\pi_{2}^{m o n}-\left(\widehat{p}_{1} Q_{1}(.)+c_{2} Q_{2}(.)\right) \leq\left(\widehat{p}_{1} Q_{1}(.)+c_{2} Q_{2}(.)-\pi_{D 1}^{*}(0,0)\right) \frac{\delta}{1-\delta} .
$$

It is useful to solve this expression for $\delta$

$$
\delta \geq \frac{\pi^{j p m}+\pi_{2}^{m o n}-\left(\widehat{p}_{1} Q_{1}(.)+c_{2} Q_{2}(.)\right)}{\pi^{j p m}+\pi_{2}^{m o n}-\pi_{D 1}^{*}(0,0)} .
$$

Since $c_{2} \geq c_{2}^{j p m}$, the term $\widehat{p}_{1} Q_{1}()+.c_{2} Q_{2}($.$) is decreasing in c_{2}$. This implies that the minimum discount factor required is increasing and collusive profits are decreasing in $c_{2}$ when $c_{2} \geq c_{2}^{j p m}$.

(ii) If $c_{2}^{m o n} \leq c_{2}<c_{2}^{j p m}, U 1-D 1$ has a collusive profit of $\widehat{p}_{1} Q_{1}()+.s c_{2} Q_{2}($.$) and a defection$ profit of $\widehat{p}_{1} Q_{1}()+c_{2} Q_{2}(.) . U 2$, has a collusive profit of $(1-s) c_{2} Q_{2}\left(p_{2}\left(c_{2}\right), \widehat{p}_{1}\left(c_{2}\right)\right)$ and a defection profit of $\pi_{2}^{m o n}$. Punishment profits are as above. Adding up the incentive constraints, we get

$$
\pi_{2}^{m o n} \leq\left(\widehat{p}_{1} Q_{1}(.)+c_{2} Q_{2}(.)-\pi_{D 1}^{*}(0,0)\right) \frac{\delta}{1-\delta},
$$

or

$$
\delta \geq \frac{\pi_{2}^{m o n}}{\widehat{p}_{1} Q_{1}(.)+c_{2} Q_{2}(.)+\pi_{2}^{m o n}-\pi_{D 1}^{*}(0,0)} .
$$

Since the term $\widehat{p}_{1} Q_{1}()+.c_{2} Q_{2}($.$) is increasing in c_{2}$, a higher $c_{2}$ in region (ii) reduces the discount factor required for collusion and yields higher collusive profits.

(iii) If $c_{2}<c_{2}^{m o n}, U 1-D 1$ has a collusive profit of $\widehat{p}_{1} Q_{1}()+.s c_{2} Q_{2}($.$) and a defection profit of$ $\widehat{p}_{1} Q_{1}()+c_{2} Q_{2}(.) . U 2$, has a collusive profit of $(1-s) c_{2} Q_{2}\left(p_{2}\left(c_{2}\right), \widehat{p}_{1}\left(c_{2}\right)\right)$ and a defection profit of $c_{2} Q_{2}^{*}$. Adding up the incentive constraints, we get

$$
c_{2} Q_{2}^{*} \leq\left(\widehat{p}_{1} Q_{1}(.)+c_{2} Q_{2}(.)-\pi_{D 1}^{*}(0,0)\right) \frac{\delta}{1-\delta}
$$

and solving for $\delta$

$$
\delta \geq \frac{c_{2} Q_{2}^{*}}{\widehat{p}_{1} Q_{1}(.)+c_{2} Q_{2}(.)+c_{2} Q_{2}^{*}-\pi_{D 1}^{*}(0,0)} .
$$

Both the numerator and the denominator are increasing in $c_{2}$ but since $\partial\left(\widehat{p}_{1} Q_{1}()+.c_{2} Q_{2}().\right) / \partial c_{2}>0$ when $c_{2}<c_{2}^{m o n}$, the numerator increases more quickly in $c_{2}$. Therefore, the minimum discount factor is decreasing in $c_{2}$ and collusive profits are increasing in $c_{2}$. 
Taking the parameter regions (i) to (iii) together, the minimum discount factor is decreasing in $c_{2}$ as long as $c_{2}<c_{2}^{j p m}$ and it is increasing in $c_{2}$ if $c_{2}>c_{2}^{j p m}$. Thus, choosing $c_{2}=c_{2}^{j p m}$ minimizes the discount factor required for collusion. As $c_{2}=c_{2}^{j p m}$ also maximizes the collusive profits, the optimal upstream price is $c_{2}=c_{2}^{j p m}$.

Step 6: Completion of the proof. We note that, from Lemma 4, the optimal downstream price conditional on $c_{2}$ is $\widehat{p}_{1}\left(c_{2}\right)$ and, from Lemma 5 , that the optimal upstream price is $c_{2}=c_{2}^{j p m}$. Hence, the overall optimal downstream price is $\widehat{p}_{1}\left(c_{2}^{j p m}\right)=p_{1}^{j p m}$. Using $c_{2}=c_{2}^{j p m}$ in the profit expressions in Lemma 3 yields the defection profits in Proposition 3. This completes the proof of Proposition 3.

\section{Appendix B: Optimal collusion with linear demand}

Step 1: Derivation of the joint-profit maximum. Proposition 3 shows that optimal collusion involves the joint-profit maximizing prices. Therefore, we need to find

$$
\underset{c_{2}, p_{1}}{\arg \max } p_{1} Q_{1}\left(p_{1}, p_{2}\right)+c_{2} Q_{2}\left(p_{2}, p_{1}\right)
$$

Assuming the linear demand function in (19), the joint profits are

$$
p_{1}\left(1-k p_{1}+d p_{2}\right)+c_{2}\left(1-k p_{2}+d p_{1}\right) .
$$

We first solve for the downstream prices. The first-order condition with respect to $p_{1}$ is $1-$ $2 k p_{1}+d p_{2}+c_{2} d=0$. $D 2$ plays the myopic best reply to $p_{1}$ given the price of the input, $c_{2} . D 2$ 's profit is $p_{2}\left(1-k p_{2}+d p_{1}\right)$, and the first-order condition is $1-2 k p_{2}+d p_{1}+k c=0$. We use these two first-order conditions to find the explicit solution for the downstream prices for a given $c_{2}$

$$
\begin{aligned}
& p_{1}=\frac{2 k+d+3 k c_{2} d}{4 k^{2}-d^{2}} \\
& p_{2}=\frac{2 k+d+c_{2}\left(2 k^{2}+d^{2}\right)}{4 k^{2}-d^{2}} .
\end{aligned}
$$

We now derive the joint-profit maximizing upstream price. Plugging the downstream prices (37) and (38) into the profit function (36) and maximizing with respect to $c_{2}$, we get

$$
c_{2}^{j p m}=\frac{(2 k+d)\left(4 k^{2}-2 d k+d^{2}\right)}{2 k(k-d)\left(8 k^{2}+d^{2}\right)}
$$


which implies the following downstream prices

$$
\begin{aligned}
p_{1}^{j p m} & =\frac{8 k^{2}+2 d k-d^{2}}{2(k-d)\left(8 k^{2}+d^{2}\right)} \\
p_{2}\left(c_{2}^{j p m}\right) & =\frac{12 k^{3}-4 d k^{2}+2 d^{2} k-d^{3}}{2 k(k-d)\left(8 k^{2}+d^{2}\right)}
\end{aligned}
$$

and outputs

$$
\begin{aligned}
Q_{1}^{j p m} & =\frac{(2 k+d)\left(4 k^{2}-d k+d^{2}\right)}{2 k\left(8 k^{2}+d^{2}\right)} \\
Q_{2}^{j p m} & =\frac{2 k^{2}+d^{2}}{8 k^{2}+d^{2}} .
\end{aligned}
$$

Given these prices and outputs, the joint maximum yields profits of

$$
p_{1}^{j p m} Q_{1}^{j p m}=\frac{(2 k+d)\left(4 k^{2}+d^{2}-d k\right)\left(8 k^{2}+2 d k-d^{2}\right)}{4 k(k-d)\left(8 k^{2}+d^{2}\right)^{2}}
$$

at the downstream level, and

$$
c_{2}^{j p m} Q_{2}^{j p m}=\frac{\left(2 k^{2}+d^{2}\right)\left(4 k^{2}-2 d k+d^{2}\right)(2 k+d)}{2 k\left(8 k^{2}+d^{2}\right)^{2}(k-d)}
$$

at the upstream level.

Step 2: Defection and punishment profits. From Proposition 3, U1-D1's defection profit is $p_{1}^{j p m} Q_{1}^{j p m}+c_{2}^{j p m} Q_{2}^{j p m}$. Its punishment profit is $\pi_{D 1}^{*}(0,0)$. $U 2$ 's defection profit is $\pi_{2}^{m o n}$, and its punishment profit is zero. Thus, we still need to derive $\pi_{2}^{m o n}$ and $\pi_{D 1}^{*}(0,0)$. Both expressions depend on downstream prices $p_{i}^{*}\left(c_{i}, c_{j}\right)$, that is, the prices that maximize the short-run profits of $D i$. With the linear demand specification, $D i$ 's profit is $\pi_{D i}=\left(1-k p_{i}+d p_{j}\right)\left(p_{i}-c_{i}\right), i, j,=1,2 ; i \neq j$ and myopic maximization at the downstream level yields Nash equilibrium prices of

$$
p_{i}^{*}\left(c_{i}, c_{j}\right)=\frac{2 k+d+2 k^{2} c_{i}+k d c_{j}}{4 k^{2}-d^{2}}
$$

and equilibrium outputs

$$
Q_{i}^{*}\left(c_{i}, c_{j}\right)=k \frac{2 k+d-\left(2 k^{2}-d^{2}\right) c_{i}+k d c_{j}}{4 k^{2}-d^{2}}
$$

(see also OSS, 1990). Downstream profits are $\pi_{D i}^{*}\left(c_{i}, c_{j}\right)=\left(Q_{i}^{*}\right)^{2} / k$. Thus we obtain

$$
\pi_{D 1}^{*}(0,0)=\frac{k}{(2 k-d)^{2}} .
$$

The monopoly price, $c_{2}^{m o n}$, maximizes $c_{2} Q_{2}^{*}\left(c_{2}, 0\right)$ and is easily derived as

$$
c_{2}^{m o n}=\frac{2 k+d}{2\left(2 k^{2}-d^{2}\right)} .
$$


The monopoly profit is

$$
\pi^{m o n}=c_{2}^{m o n} Q_{2}^{*}\left(c_{2}^{m o n}, 0\right)=\frac{(2 k+d) k}{4(d-2 k)\left(-2 k^{2}+d^{2}\right)} .
$$

Step 3: Minimum discount factors. Using (4), we obtain the following minimum discount factors

$$
\begin{aligned}
\delta_{U 1-D 1} & =\frac{(1-s) c_{2}^{j p m} Q_{2}^{j p m}}{p_{1}^{j p m} Q_{1}^{j p m}+c_{2}^{j p m} Q_{2}^{j p m}-\pi_{D 1}^{*}(0,0)} \\
& =(1-s) \frac{2(2 k-d)^{2}(2 k+d)\left(2 k^{2}+d^{2}\right)}{(k+d)\left(4 k^{2}-2 d k+d^{2}\right)\left(8 k^{2}+d^{2}\right)}
\end{aligned}
$$

and

$$
\begin{aligned}
\delta_{U 2} & =\frac{\pi^{m o n}-(1-s) c_{2}^{j p m} Q_{2}^{j p m}}{\pi^{m o n}} \\
& =1-(1-s) \frac{2\left(4 k^{2}-2 d k+d^{2}\right)\left(4 k^{4}-d^{4}\right)(2 k-d)}{k^{2}\left(8 k^{2}+d^{2}\right)^{2}(k-d)} .
\end{aligned}
$$

Step 4. Optimal markets shares. Optimal market shares should be fixed such that they minimize $\max \left\{\delta_{U 1-D 1}, \delta_{U 2}\right\}$. Since $\delta_{U 1-D 1}$ is decreasing in $s$ whereas $\delta_{U 2}$ is increasing in $s$, the optimal $s$ solves $\delta_{U 1-D 1}=\delta_{U 2}$. Explicit solutions for the optimal $s, s^{*}$, and the resulting minimum discount factor can be obtained but they are not particularly informative. These solutions are plotted in Figure 1.

\section{Appendix C: $U 2-D 2$ counter merger}

When prices are $c_{2}=c_{2}^{j p m}$ and $p_{1}=p_{1}^{j p m}, D 2$ 's profit is $\left(Q_{2}^{j p m}\right)^{2} / k$ where $Q_{2}^{j p m}$ is as in (43). The entire upstream profit is $c_{2}^{j p m} Q_{2}^{j p m}$ as in (45). The joint profit of $U 2$ and $D 2$, denoted by $\pi_{U 2-D 2}$, is $\left(Q_{2}^{j p m}\right)^{2} / k+(1-s) c_{2}^{j p m} Q_{2}^{j p m}$ or

$$
\pi_{U 2-D 2}=\left(2 k^{2}+d^{2}\right) \frac{8 k^{3}(3 / 2-s)-2 k d(2 k-d)-d^{3}(1+s)}{2 k\left(8 k^{2}+d^{2}\right)^{2}(k-d)} .
$$

The joint profit of $U 2$ and $D 2$ in the static Nash equilibrium is $k /(2 k-d)^{2}$. A counter merger will not occur if $\pi_{U 2-D 2} \geq k /(2 k-d)^{2}$.

Suppose that $s=0$, that is, $U 2$ gets the entire upstream profit. In that case

$$
\left.\pi_{U 2-D 2}\right|_{s=0}=\left(2 k^{2}+d^{2}\right) \frac{12 k^{3}-2 k d(2 k-d)-d^{3}}{2 k\left(8 k^{2}+d^{2}\right)^{2}(k-d)} .
$$


But $\left.\pi_{U 2-D 2}\right|_{s=0}<k /(2 k-d)^{2}$ as long as $d<2.614$ (where $k=d+1$ w.l.o.g.). Thus, if products are sufficiently heterogenous, charging $c_{2}=c_{2}^{j p m}$ and $p_{1}=p_{1}^{j p m}$ induces the counter merger even if $U 2$ gets all the upstream profit.

Suppose next that $d \geq 2.614$ such that $\left.\pi_{U 2-D 2}\right|_{s=0} \geq k /(2 k-d)^{2}$. We can calculate the maximum upstream market share $U 1-D 1$ may get such that $U 2-D 2$ do not find the counter merger worthwhile. This level of $s$ is

$$
s=-\frac{8 k^{5}+4 k^{4} d-22 k^{3} d^{2}+4 k^{2} d^{3}-4 d^{4} k+d^{5}}{(2 k+d)\left(2 k^{2}+d^{2}\right)(2 k-d)^{2}}
$$

which is non-negative if and only if $d \geq 2.614$. One can show that this level of $s$ is smaller than the $s^{*}$ in Figure 1 that minimizes the critical discount factor. That is, in order to prevent the counter merger, $U 2$ 's market share $(1-s)$ must be larger than $1-s^{*}$. Thus, when firms charge $c_{2}=c_{2}^{j p m}$ and $p_{1}=p_{1}^{j p m}$, they cannot prevent the counter merger.

Finally, consider the claim that $c_{2}=c_{2}^{*}$ and an appropriately chosen $s$ will actually prevent the counter merger. OSS $\left(1990\right.$, p. 141) show that the input price $c_{2}^{*}=(2 k+d) d^{2} /\left(2 k^{2}\left(2 k^{2}-d^{2}\right)\right)$ is sufficiently low to prevent $U 2$ and $D 2$ from integrating. As for the downstream price, set $p_{1}=\widehat{p}_{1}\left(c_{2}^{*}\right)$ as in (26). Setting $c=c_{2}^{*}$ and $p_{1}=\widehat{p}_{1}\left(c_{2}^{*}\right)$ yields

$$
\pi_{U 2-D 2}=\frac{\left(4 k^{4}-4 d^{2} s k^{2}+d^{4}(1+s)\right)\left(2 k^{4}-2 d^{2} k^{2}+d^{4}\right)}{2 k^{3}(2 k-d)^{2}\left(2 k^{2}-d^{2}\right)^{2}} .
$$

Now from

$$
\pi_{U 2-D 2}-k /(2 k-d)^{2}=d^{2} \frac{4 k^{4} d^{2}-8 s k^{6}+10 d^{2} s k^{4}-6 d^{4} s k^{2}-2 d^{4} k^{2}+d^{6}+d^{6} s}{2 k^{3}(2 k-d)^{2}\left(2 k^{2}-d^{2}\right)^{2}}
$$

and

$$
\pi_{U 2-D 2}-k /\left.(2 k-d)\right|_{s=0}=\frac{1}{2} d^{2} \frac{4 k^{4} d^{2}-2 d^{4} k^{2}+d^{6}}{k^{3}(2 k-d)^{2}\left(2 k^{2}-d^{2}\right)^{2}}>0
$$

it follows that there always exist a sufficiently low but positive level of $s$ that deters the counter merger.

\section{Appendix D: Downstream collusion}

We will analyze the symmetric case where both downstream firms choose a collusive price of $p$. Thus, collusive profits are $(1-k p+d p) p$ for each downstream firm. By defecting, a downstream firm can obtain a profit of $(1+d p)^{2} / 4 k$. Static Nash profits are $k /(2 k+d)^{2}$ as seen above for $D 1$. 
Plugging these profit expressions into (4), we get

$$
\delta_{D i}=\frac{\frac{(1+d p)^{2}}{4 k}-(1-k p+d p) p}{\frac{(1+d p)^{2}}{4 k}-\frac{k}{(2 k-d)^{2}}}=\frac{(p(2 k-d)-1)(2 k-d)^{2}}{d\left(p\left(2 k d-d^{2}\right)+4 k-d\right)} .
$$

Evaluating this expression at the static Nash price, $p=1 /(2 k-d)$, yields $\delta=0$. The minimum discount factor is monotonically increasing in $p$. Evaluating this expression at the joint-profit maximizing downstream price, $p=1 / 2(k-d)$, yields $\delta \geq 1 / 2$.

In order to obtain Figure 2, we invert (61) and get the highest sustainable collusive downstream price as a function of $\delta$. Plugging this expression into $(1-k p+d p) p$ yields a functional form for the collusive profit as a function of $\delta$.

\section{References}

[1] Abreu, D., 1988. On the Theory of Infinitely Repeated Games with Discounting. Econometrica $56,383-396$.

[2] Bernheim, D.C., Whinston, M.D., 1990. Multimarket Contact and Collusive Behavior. RAND Journal of Economics 39, 191-225.

[3] Bolton, P., Whinston, M.D., 1993. Incomplete Contracts, Vertical Integration and Supply Assurance. Review of Economic Studies 60, 121-148.

[4] Bonanno, G., Vickers, J., 1988: Vertical Separation, Journal of Industrial Economics, 36(3), 257-265.

[5] Chen, Y., 2001. On Vertical Mergers and Their Competitive Effects. RAND Journal of Economics 32, 466-496.

[6] Chen, Y., Riordan, M.H., 2007. Vertical Integration, Exclusive Dealing and Ex Post Cartelization. RAND Journal of Economics 38, 1-21.

[7] Choi, J.P., Yi, S.-S., 2000. Vertical Foreclosure and the Choice of Input Specifications. RAND Journal of Economics 31, 717-743.

[8] Church, J., Gandal, N., 2000. Systems Competition, Vertical Merger, and Foreclosure. Journal of Economics and Management Strategy 9, 25-51.

[9] Compte, O., Jenny, F., Rey, P., 2002. Capacity Constraints, Mergers and Collusion. European Economic Review 46, 1-29.

[10] Cooper, J.C., Froeb, L.M., O'Brien, D., Vita, M.G., 2005. Vertical antitrust policy as a problem of inference. International Journal of Industrial Organization 23, 639-664.

[11] Deneckere, R., 1983. Duopoly supergames with product differentiation. Economics Letters 11, $37 ? 42$

[12] Hart, O., Tirole, J., 1990. Vertical Integration and Market Foreclosure. Brookings Papers on Economic Activity, Microeconomics, 205-276.

[13] Iyer, G., Villas-Boas, J.M., 2003. A Bargaining Theory of Distribution Channels. Journal of Marketing Research 40, 80-100. 
[14] Inderst, R., Valetti, T., 2007. Buyer Power and the "Waterbed Effect". Working Paper, London School of Economics.

[15] Martin, S., Normann, H.T., Snyder, C.M., 2001. Vertical Foreclosure in Experimental Markets. RAND Journal of Economics 32, 466-96.

[16] Milliou, C., Petrakis, E., Vettas, N. 2005. (In)efficient Trading Forms in Competing Vertical Chains. Mimeo.

[17] Nocke, V., White, L., 2003. Do Vertical Mergers Facilitate Upstream Collusion? Penn Institute for Economic Research Working Paper \#03-033.

[18] Nocke, V., White, L., 2007. Do Vertical Mergers Facilitate Upstream Collusion? American Economic Review, 97, 1321-1339.

[19] Normann, H.T., 2004. Equilibrium Vertical Foreclosure in the Repeated Game. SSRN Working Paper \#585363.

[20] O’Brien, D.P., Shaffer, G., 1992. Vertical Control with Bilateral Contracts. RAND Journal of Economics 23, 299-308.

[21] Ordover, J.A., Saloner, G., Salop, S.C., 1990. Equilibrium Vertical Foreclosure. American Economic Review 80, 127-42.

[22] Ordover, J.A., Saloner, G., Salop, S.C., 1992. Equilibrium Vertical Foreclosure: Reply. American Economic Review 82, 698-703.

[23] Radner, R. and Ichiishi, T. (1999). A Profit-Center Game with Incomplete Information. Review of Economic Design 4, 307-343.

[24] Reiffen, D., 1992. Equilibrium Vertical Foreclosure: Comment. American Economic Review $82,694-97$.

[25] Rey, P., Tirole, J., 2007. A Primer on Foreclosure. In: M. Armstrong, Porter, R. (Eds.), Handbook of Industrial Organization, vol. III., North Holland, pp. 2145-2220.

[26] Riordan, M.H., 1998. Anticompetitive Vertical Integration by a Dominant firm. American Economic Review 88, 1232-48.

[27] Riordan, M.H., 2008. Competitive Effects of Vertical Integration. In: Buccirossi, P. (Ed.), Handbook of Antitrust Economics, MIT Press, pp. 145-182.

[28] Riordan, M.H., Salop, G., 1995. Evaluating Vertical Mergers - A Post Chicago Approach. Antitrust Law Journal 63, 513-568.

[29] Salinger, M., 1988. Vertical Mergers and Market Foreclosure, The Quarterly Journal of Economics 103, 345-356.

[30] Tirole, J., 1988. The Theory of Industrial Organiztion, MIT Press.

[31] Vives, X., 1999. Oligopoly Pricing - Old Concepts and New Ideas. MIT Press. 